\title{
Avaliação do comprometimento orofacial nos pacientes com lúpus eritematoso sistêmico juvenil
}

Dissertação apresentada à Faculdade de Medicina da Universidade de São Paulo para obtenção do título de Mestre em Ciências

Área de concentração: Pediatria Orientador: Dr. Clovis Artur Almeida da Silva

São Paulo

2006 


\section{FICHA CATALOGRÁFICA}

Preparada pela Biblioteca da

Faculdade de Medicina da Universidade de São Paulo

Creprodução autorizada pelo autor

Fernandes, Elisabeth Gonzaga Canova

Avaliação do comprometimento orofacial nos pacientes com lúpus

eritematoso sistêmico juvenil / Elisabeth Gonzaga Canova Fernandes. -- São Paulo, 2006.

Dissertação(mestrado)--Faculdade de Medicina da Universidade de São Paulo.

Departamento de Pediatria.

Área de concentração: Pediatria.

Orientador: Clovis Artur Almeida da Silva.

Descritores: 1.LÚPUS ERITEMATOSO SISTÊMICO 2.ASSISTÊNCIA ODONTOLÓGICA PARA DOENTES CRÔNICOS 3.GENGIVITE 4.ARTICULAÇÃO TEMPOROMANDIBULAR 5.CRIANÇA 6.ADOLESCENTE

USP/FM/SBD-120/06 
Ao meu marido, Maurício, pela paciência, companheirismo e sobretudo pelo amor incondicional que tem demonstrado nestes anos de convívio e que nos une a cada dia mais.

À nossa filha, Júlia, que muito me incentivou, mesmo que inconscientemente, através dos seus gestos simples, das suas palavras puras e do seu sorriso contagiante.

Aos meus queridos pais, Nise e Albert, pelo exemplo de amor, dedicação, incentivo e pela confiança em meu potencial. 
Ao $\mathrm{Dr}$ Clovis Artur Almeida Silva, pela sua excelente orientação, por sua enorme contribuição à minha vida acadêmica e reconhecimento pela sua dedicação, ética, sabedoria e humanismo. 


\section{AGRADECIMENTOS}

Aos pacientes lúpicos e seus pais pela colaboração na realização deste trabalho.

Aos Profs Drs Yassuhiko Okay, Flavio Adolfo Costa Vaz, Magda M. Sales Carneiro Sampaio e Sandra Grisi pelo apoio.

Ao Dr José Tadeu Tesseroli Siqueira pelo empenho, incentivo, e importante contribuição neste trabalho.

À Dra Cynthia Savioli, pela realização do exame odontológico dos pacientes e pela sua enorme dedicação e sua ajuda sempre atenciosa.

Às assistentes da Unidade de Reumatologia Pediátrica do ICr HC FMUSP Adriana Maluf Elias Sallum, Ana Paola Navarrette Lotito, Bernadete de Lourdes Liphaus e Lúcia Maria de Arruda Campos pela contribuição no meu aprendizado como reumatologista pediátrica.

Aos colegas da Unidade de Reumatologia Pediátrica:, Adriana, Aline, Ana Júlia, Aura, Daniela, Francine, Georgiana, Juliana, Luciana, Marília, Mércia, Nadyesda, Pollyana, Renata, Ricardo, Rosa, e pelo grande apoio e pelos momentos divertidos vividos juntos.

Aos assistentes, aprimorandos e funcionários da Divisão de Odontologia do HC FMUSP pelo apoio.

Ao Dr. Ulisses Dória Filho por seu auxílio na realização da análise estatística.

Ao Dr Marcelo Valente pela sua ajuda na realização e interpretação dos exames radiológicos.

Aos Profs Drs Lilian Cristófani, Vera Koch e Paulo Maluf pelas valiosas sugestões na banca de qualificação. 
Ao Nivaldo e Milene Rocha pelo incentivo e apoio.

À equipe da Biblioteca, pricipalmente à Mariza, pela ajuda nas pesquisas bibliográficas.

À equipe do apoio didático pelo profissionalismo.

À equipe do CONDIR pela ajuda e atençao.

À equipe do SAME e arquivo médico pela aquisição dos prontuários.

A todos da minha família pela presença e estímulo constantes.

Aos meus amigos da Faculdade de Medicina ABC, em especial para Daniela Isoyama, Daniela Tanigushi, Elisangela Grigio, Keila, Kamoto e Regina Munekata pelo carinho, palavras de estímulo e pela sincera amizade.

Aos meus colegas do Hospital e Maternidade Cristóvão da Gama e Prefeitura Municipal de Santo André pelo apoio e incentivo.

A todos vocês, MUITO OBRIGADA! 


\section{NORMATIZAÇÃO ADOTADA}

Esta tese está de acordo com :

Referências: Adaptado do International Committee of Medical Journals Editors (Vancouver).

Universidade de São Paulo. Faculdade de Medicina. Serviço de Biblioteca e Documentação. Guia de apresentação de dissertações, teses e monografias. Elaborado por Annelise Carneiro da Cunha, Maria Julia de A. L. Freddi. Maria F Crestana, Marinalva de Souza Aragão, Suely Campos Cardoso, Valéria Vilhena. São Paulo: Serviço de Biblioteca e Documentação; 2004.

Abreviaturas dos títulos dos periódicos de acordo com o List of Journals Indexed in Index Medicus. 


\section{SUMÁRIO}

Lista de abreviaturas e siglas

Lista de tabelas

Lista de figuras

Resumo

Summary

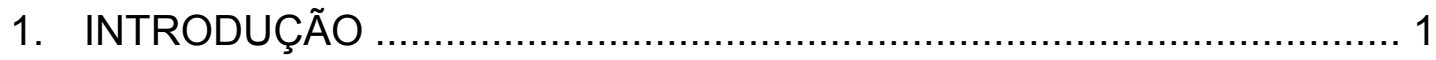

1.1 Sistema mastigatório...................................................... 4

1.1.1 Dentes e Oclusão ....................................................... 5

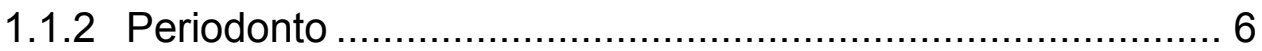

1.1.3 Articulação Temporomandibular (ATM) f....................... 8

1.2 Comprometimento orofacial nos pacientes com LESJ.................. 8

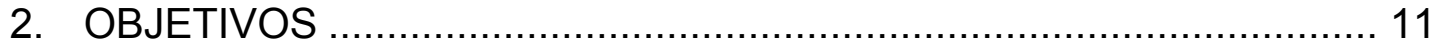

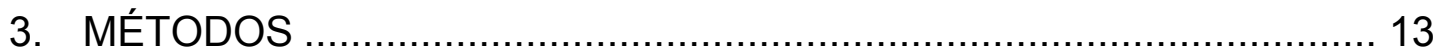

3.1 ANÁLISE ESTATÍSTICA ................................................ 19

4. RESULTADOS ......................................................................... 20

4.1 Características orofaciais dos pacientes com LESJ.................... 26

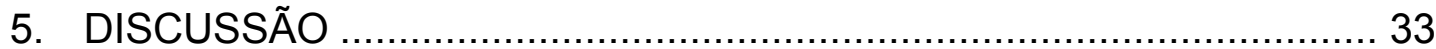

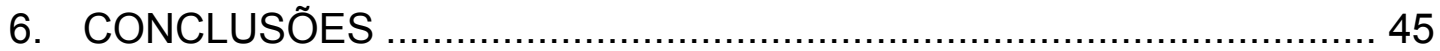

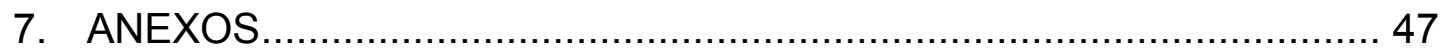

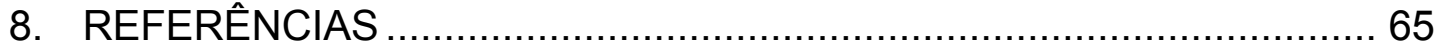




\section{LISTA DE ABREVIATURAS E SIGLAS}

ACR

AlJ

ATM

CPO-D

DTM

FMUSP

HC

$\mathrm{ICr}$

IDC

IMM

IP

IS

LES

LESJ

SLEDAI

SLICCIACR-DI

TCLE
American College of Rheumatology

Artrite idiopática juvenil

Articulação temporomandibular

Índice de número de dentes cariados, perdidos ou obturados

Disfunção temporomandibular

Faculdade de Medicina da Universidade de São Paulo

Hospital das Clínicas

Instituto da Criança

Índice de disfunção clínica

Índice de mobilidade mandibular

Índice de placa

Índice de sangramento gengival

Lúpus eritematoso sistêmico

Lúpus eritematoso sistêmico juvenil

Systemic lupus erythematosus disease activity index

Systemic lupus international collaborating clinics/ ACR

Termo de Consentimento Livre e Esclarecido 


\section{LISTA DE TABELAS}

Tabela 1 - Características demográficas dos pacientes com lúpus eritematoso sistêmico juvenil (LESJ) e grupo controle submetidos à avaliação orofacial

Tabela 2 - Distribuição dos índices CPO-D, de placa e sangramento gengival nos pacientes com lúpus eritematoso sistêmico juvenil (LESJ) e grupo controle.

Tabela 3 - Características da relação molar e perfil facial nos pacientes com lúpus eritematoso sistêmico juvenil (LESJ) e grupo controle

Tabela 4 - Características do índice de Helkimo nos pacientes com lúpus eritematoso sistêmico juvenil (LESJ) e grupo controle .....24

Tabela 5 - Distribuição da presença do índice de disfunção clínica de Helkimo nos pacientes com lúpus eritematoso sistêmico juvenil (LESJ) e grupo controle

Tabela 6 - Distribuição da amplitude inadequada do índice de mobilidade mandibular de Helkimo nos pacientes com lúpus eritematoso sistêmico juvenil (LESJ) e grupo controle .....25

Tabela 7 - Características orofaciais dos pacientes com lúpus eritematoso sistêmico juvenil (LESJ) de acordo com a atividade da doença.

Tabela 8 - Características orofaciais dos pacientes com lúpus eritematoso sistêmico juvenil (LESJ) de acordo com o dano cumulativo da doença

Tabela 9 - Características orofaciais dos pacientes com lúpus eritematoso sistêmico juvenil (LESJ) com relação a utilização de imunossupressores 


\section{LISTA DE FIGURAS}

Figura 1 - Desenho esquemático da relação entre os primeiros molares- Classificação de Angle.

Figura 2 - Correlação entre tempo de doença e índice de placa nos pacientes com lúpus eritematoso sistêmico juvenil (LESJ). .28

Figura 3 - Correlação entre tempo de doença e índice de sangramento gengival nos pacientes com lúpus eritematoso sistêmico juvenil (LESJ)

Figura 4 - Correlação entre índice de placa e índice de sangramento gengival nos pacientes com lúpus eritematoso sistêmico juvenil (LESJ)

Figura 5 - Correlação entre dose de prednisona e índice de placa nos pacientes com lúpus eritematoso sistêmico juvenil (LESJ)

Figura 6 - Correlação entre dose de prednisona e índice de sangramento gengival nos pacientes com lúpus eritematoso sistêmico juvenil (LESJ) 


\section{RESUMO}

Fernandes, EGC. Avaliação do comprometimento orofacial nos pacientes com lúpus eritematoso sistêmico juvenil [Dissertação]. São Paulo: Faculdade de Medicina, Universidade de São Paulo; 2006. 74p.

INTRODUÇÃO: Com a melhora do prognóstico nos pacientes com lúpus eritematoso sistêmico juvenil novas recomendações são necessárias na reumatologia pediátrica, como avaliação da saúde bucal e do sistema mastigatório. O objetivo deste estudo é avaliar o comprometimento orofacial nos pacientes com lúpus eritematoso sistêmico juvenil e grupo controle, e avaliar possíveis associações entre o comprometimento orofacial e manifestações clínicas, exames laboratoriais e terapias da doença. MÉTODOS: Entre março de 2004 e julho de 2005 foram avaliados 48 pacientes com diagnóstico de lúpus eritematoso sistêmico juvenil, atendidos na Unidade de Reumatologia Pediátrica do ICr-HC-FMUSP. O grupo controle incluiu 48 crianças e adolescentes saudáveis atendidos na Divisão de Odontologia do HC-FMUSP. A pesquisa incluiu avaliação de dados sóciodemográficos, manifestações clínicas, exames laboratoriais, atividade da doença (SLEDAI), dano cumulativo (SLICC/ACR-DI) e terapias da doença. A avaliação orofacial incluiu questionário de anamnese, índice CPO-D, índice de placa, índice de sangramento gengival, relação dentária, perfil facial, índice de Helkimo e avaliação da articulação temporomandibular através da radiografia panorâmica de face em todos os pacientes e tomografia computadorizada apenas nos casos com achatamento e/ou destruição dos côndilos mandibulares. RESULTADOS: Os dois grupos foram homogêneos com relação à faixa etária, distribuição por gênero e classe sócio-econômica. A idade dos pacientes com lúpus eritematoso sistêmico juvenil variou de 87 a 218 meses (média de 161,9 938,4 ) e do grupo controle de 78 a 254 meses (média de 154,4 $\pm 45,8 ; p=0,384$ ). As medianas dos índices de placa e de sangramento gengival nos pacientes com lúpus eritematoso sistêmico juvenil foram superiores em relação aos controles $(61,5 \times 38,1 ; p=0,003$ e 26,0X15,95; $p=0,014)$. O índice de disfunção clínica e o índice de mobilidade mandibular mostraram-se mais alterados nos pacientes com LESJ versus controles $(p=0,002$, $p=0,025)$. Correlação linear estatística foi evidenciada entre: tempo de doença e índice de sangramento gengival $(p=0,017 ; r=0,11)$, dose cumulativa de prednisona e índice de placa $(p=0,010, r=0,385)$ e dose cumulativa de prednisona e índice de sangramento gengival $(p=0,001, r=0,02)$. A mediana do índice de mobilidade mandibular foi superior nos pacientes com lúpus eritematoso sistêmico juvenil em uso de um ou mais imunossupressores em relação aos que não utilizaram estas drogas $(p=0)$. Apenas dois pacientes apresentaram radiografia panorâmica com achatamento e/ou destruição dos côndilos mandibulares e na tomografia computadorizada de ATM os achados foram: redução do espaço articular bilateralmente, erosões dos platôs articulares com aplainamento dos côndilos sugestivo de necrose avascular da articulação temporomandibular. CONCLUSÕES: Os pacientes com lúpus eritematoso sistêmico juvenil apresentaram uma precária higiene oral, maior freqüência de gengivite e disfunção da articulação temporomandibular em relação ao grupo controle. Os pacientes com maior tempo de doença e maior dose cumulativa de prednisona tiveram maior freqüência de gengivite e os que utilizaram imunossupressores apresentaram disfunção da articulação temporomandibular.

DESCRITORES: 1.Lúpus eritematoso sistêmico, 2.assistência odontológica para doentes crônicos, 3.gengivite, 4.articulação temporomandibular, 5.criança, 6.adolescente. 


\section{SUMMARY}

Fernandes, EGC. Analysis of dental and facial endangering of patients with juvenile systemic lupus erythematosus [Thesis]. São Paulo: Faculdade de Medicina, Universidade de São Paulo; 2006. 74p.

INTRODUCTION: Given the enhanced prognosis of patients with juvenile systemic lupus erythematosus, new recommendations are necessary in pediatric rheumatology, such as the analysis of oral health and the masticatory system. The aim of this study was to compare dental and facial conditions of patients with juvenile systemic lupus erythematosus and a control group, and to evaluate a potential relationship between dental and facial endangering and clinical manifestations, laboratory tests and therapies for the disease. PATIENTS AND METHODS: A total of 48 children and adolescents with juvenile systemic lupus erythematosus attending the Pediatric Rheumatology Unit of the Children's Institute of our University Hospital were studied between January 2004 and July 2005. The control group included 48 healthy children and adolescents that were selected from the Odontology Division of our University Hospital. The search included the analysis of social and demographic data, clinical manifestations, laboratory tests, juvenile systemic lupus erythematosus disease activity and cumulative damage (using the SLEDAI and the SLICC/ACR-DI), and therapies. The dental and facial examination included the anamnesis questionnaire, DMFT index, plaque and gengival bleeding index, dental relationship, facial profile, Helkimo's index and evaluation of the temporomandibular joint through a radiographic panoramic examination of all patients and a computer tomography on those with flattening and/or destruction of the mandibular condyles. RESULTS: The two groups were homogeneous regarding age, gender and social-economic class. The age of the juvenile systemic lupus erythematosus patients ranged from 87 to 218 months (mean of $161.9 \pm 38.4$ ) and of the control group from 78 a 254 months (mean of 154.4 $\pm 45.8 ; p=0.384$ ). The medians of the plaque and gingival bleeding indexes were higher in juvenile systemic lupus erythematosus patients than in the control group $(61.5 \times 38.10$; $p=0.003$ and 26.0X15.95; $p=0.014)$. The indexes of clinical dysfunction and mandibular mobility were higher in juvenile systemic lupus erythematosus patients versus the control group $(p=0,002, p=0,025)$. A linear statistical correlation was evidenced between: juvenile systemic lupus erythematosus duration and the gingival bleeding index $(p=0.017 ; r=0.11)$, cumulative dose of prednisone and the plaque index $(p=0,010 ; r=0.385)$ and cumulative dose of prednisone and the gingival bleeding index $(p=0.001, r=0.02)$. The median of the mandibular mobility index was higher in juvenile systemic lupus erythematosus patients that used at least one imunossupressive drugs compared with those that didn't use this medication $(p=0)$. Only two patients showed a panoramic radiography with flattening and/or destruction of the mandibular condyles. The computer tomography revealed: narrowing of joint spaces bilaterally and erosions of joints plateaus with flattening of condyles that suggested avascular necrosis of temporomandibular joint. CONCLUSIONS: Juvenile systemic lupus erythematosus patients presented poor oral hygiene, higher incidence of gingivitis and temporomandibular joint dysfunction compared to the control group. Patients with longer disease duration and higher cumulative dose of prednisone had a greater incidence of gingivitis, and those who used imunossupressives drugs showed temporomandibular joint dysfunction.

DESCRIPTORS: 1.Systemic lupus erythematosus, 2.dental care for chronically ill, 3.gingivitis, 4.temporomandibular joint, 5.child, 6.adolescent. 


\section{INTRODUÇÃO}


O lúpus eritematoso sistêmico (LES) juvenil (LESJ) é uma doença rara, com incidência anual nos Estados Unidos da América estimada em 0,6 casos/100.000crianças e adolescentes, com pico entre 11 e 15 anos de idade, sendo excepcional antes dos cinco anos (Cassidy et al., 2001; Hilário et al., 2002). A proporção entre meninas e meninos varia de 2 a 3:1 em prépúberes a 8:1 na fase pós puberal (Lehman et al.,1989).

A sua etiopatogenia permanece desconhecida. No entanto, sabe-se que a combinação de vários fatores, em pacientes geneticamente predispostos, [tais como: auto-imunidade (Campos et al., 2003), infecções virais, drogas, fatores hormonais, psíquicos e ambientais] propiciam as alterações nos mecanismos imunorreguladores responsáveis pelas manifestações do LESJ (Lehman, 2001; Cassidy et al., 2001; Liphaus et al., 2002).

A característica principal do LESJ é o acometimento de múltiplos órgãos e sistemas com várias formas de apresentação. O início dos sintomas pode ser insidioso, de pequena gravidade ou abrupto com envolvimento importante de órgãos e sistemas. De maneira geral é uma doença de evolução imprevisível, intercalando períodos de exacerbação e remissão das manifestações clínicas, sendo as reativações causadas na maioria das vezes por infecções (Lehman, 2001). 
O tratamento do LESJ é um grande desafio porque nenhuma intervenção terapêutica determina cura da doença. As exacerbações da doença podem ocorrer após anos de manutenção estável e os eventos adversos dos fármacos podem ser tão ou mais importantes que a própria doença. Os corticosteróides e os antimaláricos (cloroquina ou hidroxicloroquina) constituem a base do tratamento medicamentoso de crianças e adolescentes com LESJ (Silva, 2004; Facó et al., 2005). A pulsoterapia com metilprednisolona é utilizada em situações de gravidade. Os imunossupressores (pulsoterapia endovenosa com ciclofosfamida, metotrexato, ciclosporina, micofenolato mofetil e/ou azatioprina) são reservados para pacientes com doença grave refratária ou com eventos adversos aos corticosteróides e antimaláricos (Lehman 1995; Lehman, 2001).

O prognóstico em crianças e adolescentes com LESJ é em geral mais reservado que em adultos, com maior freqüência de acometimento renal e neurológico (Lehman, 2001). Infecção, habitualmente associada à atividade da doença, é a principal causa de óbito destes pacientes (Canova et al., 2002; Facó et al., 2005). Esse quadro vem se modificando nos últimos 30 anos, não só devido ao diagnóstico precoce, possível pelo melhor reconhecimento clínico da doença, com estabelecimento de critérios diagnósticos e pela introdução de testes laboratoriais com maior especificidade para o LESJ, mas também pelo surgimento de modalidades terapêuticas mais efetivas para tratar a doença (imunossupressores, hemodiálise e transplante renal) e suas complicações (novos antibióticos, drogas hipotensoras mais eficazes, etc) (Brandão et al., 1994; Appenzeller et al., 2005). 
Atualmente, a taxa de sobrevida de cinco anos no LESJ vem se mantendo em 85 a $88 \%$ das crianças e adolescentes lúpicos com nefrite, chegando a 10 anos entre 60 a 65\% (Mc Curdy et al., 1992; Lehman, 2001). Cameron (1993) relatou sobrevivência de 70 a $80 \%$ das crianças com mais de 15 anos de doença. Appenzeller et al. (2005) evidenciaram sobrevida de 44\% das crianças e adolescentes em 20 anos de LESJ, seguidos na Universidade Estadual de Campinas, São Paulo.

Com a melhora do prognóstico e sobrevida dos pacientes com LESJ, novas recomendações são necessárias nos ambulatórios de reumatologia pediátrica, tais como: avaliação rotineira de osteoporose, avaliação dos fatores de risco de aterosclerose e infarto agudo do miocárdio, orientação sexual, anticoncepção; assim como avaliação do sistema mastigatório e da saúde bucal destes pacientes, com adequado acompanhamento odontológico (De Rossi et al., 1998; Hughes et al., 1998).

\subsection{SISTEMA MASTIGATÓRIO}

O sistema mastigatório compreende bases ósseas (maxila e mandíbula), articulação temporomandibular (ATM), periodonto, osso alveolar, dentes, sistema neuromuscular e ligamentos. Para que este sistema seja funcionalmente adequado é necessário que seus componentes estejam em perfeito equilíbrio (Viola et al., 1996). 


\subsubsection{Dentes e Oclusão}

Os dentes podem interferir no equilíbrio do sistema mastigatório através de patologias dentárias e de seu posicionamento no arco.

A patologia mais comum que afeta os dentes é a cárie dentária que é um processo mediado por microorganismos como Streptococcus mutans, Lactobacillus sp e Actinomyces sp (Corby et al., 2005). A cárie é caracterizada pela desmineralização da parte inorgânica e destruição da parte orgânica. Os fatores essenciais para sua ocorrência são: dieta, estrutura do próprio dente e microorganismos. Os fatores secundários são: higiene oral e saliva. Inicialmente o processo de cárie atinge estruturas dentárias mais superficiais como esmalte e dentina. Na medida em que o processo evolui pode atingir a polpa dental, favorecendo a invasão bacteriana, produzindo necrose e podendo evoluir para um abscesso dentoalveolar (Reich et al., 1999).

Quanto ao posicionamento, os dentes relacionam-se nos arcos dentários harmoniosamente entre si, caracterizando a oclusão fisiológica. Quando esta relação não é adequada resulta em má oclusão, podendo causar danos ao sistema mastigatório (English et al., 2002). A classificação de Angle (English et al., 2002), considera a relação dos primeiros molares permanentes como "chave de oclusão". Baseado na "chave de oclusão", na qual a cúspide mésio vestibular do primeiro molar superior oclui com o sulco vestibular do primeiro molar inferior, Angle classificou as anomalias de oclusão dental em três classes (Figura 1): classe I (relação molar em "chave 
de oclusão", podendo haver apinhamento em dentes anteriores), classe II (o primeiro molar inferior está em uma posição distal em relação ao primeiro molar superior) e classe III (o primeiro molar inferior está mesialmente colocado em relação ao primeiro molar superior). Na dentição decídua, a "chave de oclusão" se estabelece entre os segundos molares decíduos.

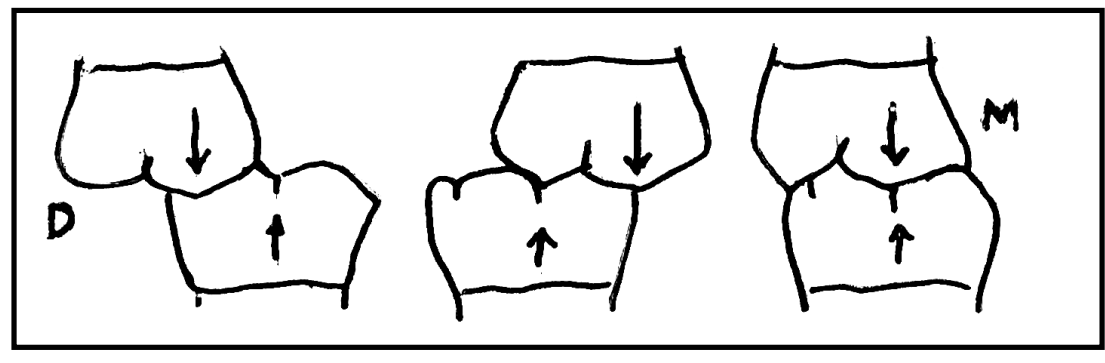

Classe III

Classe II

Classe I

Figura 1 - Desenho esquemático da relação entre os primeiros molaresClassificação de Angle (D - distal, M - mesial).

À esquerda evidencia molar inferior mesialmente colocado em relação ao superior (Classe III de Angle), ao centro há distalização do molar inferior (Classe II de Angle) e à direita estas relações são normais (Classe I de Angle).

\subsubsection{Periodonto}

O dente é suportado pelo osso alveolar através de um sistema ligamentar: o periodonto. Este compreende os seguintes tecidos: gengiva, ligamento periodontal, cemento radicular e osso alveolar. A relação denteperiodonto é uma articulação semi-rígida do tipo gonfose, ricamente vascularizada e inervada, principalmente por mecanoceptores e participa 
ativamente da sensibilidade táctil do aparelho mastigatório. O periodonto é acometido, numa maior freqüência, por lesões infecciosas ou traumáticas, mas também pode sofrer alterações decorrentes de síndromes congênitas e doenças auto-imunes (Albandar, 2005).

Dentre as lesões infecciosas, estão a gengivite e a periodontite. A gengivite é caracterizada pelo estado inflamatório dos tecidos gengivais quando expostos à placa bacteriana. A periodontite representa a perda do osso alveolar e o dano extenso às fibras do ligamento periodontal, com migração do epitélio juncional e manifestações disseminadas do processo inflamatório e imunopatológico nos tecidos. Essas doenças apresentam um acúmulo de placa bacteriana associado a fatores de risco, tais como: componente genético de susceptibilidade a doença periodontal, idade, doenças sistêmicas com imunodeficiências primárias ou secundárias, fumo e presença de determinadas bactérias na placa bacteriana. A instalação, permanência e progressão da doença periodontal dependerá basicamente desses fatores (Albandar, 2005, Oh et al., 2002, Dibart, 1997).

Alguns medicamentos como bloqueadores de canal de cálcio, anticonvulsivantes e imunossupressores podem causar hipertrofia gengival, como uma manifestação periodontal (Oh et al., 2002). A ação sistêmica da ciclosporina determina um acúmulo de colágeno e proteínas não colagenosas; com acantose e hipertrofia do estroma gengival, resultando em aumento gengival entre 10 e $70 \%$ dos pacientes dependendo da dose utilizada (Albandar, 2005). 


\subsubsection{Articulação Temporomandibular (ATM)}

A ATM é uma articulação sinovial, com movimentos complexos de abertura, fechamento, lateralidade, retrusão e protrusão, em que há rotação e translação do côndilo mandibular. Essa articulação é formada pela cavidade articular do osso temporal e pelo côndilo mandibular que são revestidas por tecido fibroso. As superfícies articulares são separadas pelo disco articular que divide a articulação em dois compartimentos (superior e inferior), estão envolvidas por uma cápsula de tecido fibroso, onde internamente encontra-se a membrana sinovial que secreta o líquido sinovial responsável por lubrificar as superfícies articulares e reduzir riscos de erosão óssea (Siqueira, 2001).

Sinais e sintomas comuns relacionados à disfunção articular são: odontalgia, ruídos articulares, limitação de abertura bucal, dor a função, alteração dos movimentos mandibulares e alterações radiográficas (Bonjardim et al., 2003, Siqueira et al., 2003, Vanderas et al., 2002).

\subsection{COMPROMETIMENTO OROFACIAL NOS PACIENTES COM LESJ}

Úlceras orais estão entre os critérios do American College of Rheumatology (ACR) para a classificação do LESJ (Hochberg, 1997). As lesões de mucosa oral são relativamente comuns nos pacientes com LESJ e sua incidência varia entre 20 e 50\%, sendo associadas com atividade clínica 
da doença, embora sem alterações significativas nos exames laboratoriais (Cassidy et al., 2001; Lehman, 2001). As lesões orais podem se manifestar das mais diversas formas, tais como: úlceras, lesões discóides, leucoplasia, queilite, glossite e eritemas não ulcerados, o que às vezes dificulta o correto diagnóstico (Orteu et al., 2001; Burge et al., 1989; Jonsson et al., 1984;). As úlceras são classicamente indolores e se localizam preferencialmente no palato duro. Entretanto, as úlceras podem também se formar nos lábios, palato mole, língua, gengiva e mais raramente no septo nasal anterior e evoluir com perfuração nasal assintomática (Mutlu et al., 1993). Os dentes e o periodonto podem ser comprometidos no paciente com LES (Nagler et al., 1999) podendo dificultar uma adequada manutenção da saúde bucal, favorecendo maior prevalência de doenças bucais (Romanides et al., 1999; Peterson et al., 1980). Rhodus et al. (1990) relataram uma incidência de xerostomia em $100 \%$ dos pacientes com LES estudados, afetando mastigação, lubrificação, deglutição e paladar.

Manifestações articulares, como artrite ou artralgia, têm alta incidência (entre 70 e 80\%), constituindo uma das manifestações mais freqüentes na apresentação inicial da doença (Lehman, 2001). O acometimento da ATM é pouco diagnosticado, porque habitualmente não é pesquisado corretamente e o quadro clínico pode variar do assintomático até dor articular localizada mimetizando otite ou mastoidite. A artrite do LESJ não costuma ser erosiva, entretanto na literatura há relatos de casos raros de artrite erosiva de ATM associado a pacientes adultos com LES (Tuggle, 1985; Jonsson et al., 1983; Liebling et al., 1981) 
A incidência do comprometimento orofacial nos pacientes com artrite idiopática juvenil (AIJ) ocorre entre 50 e 60\%. Estudos realizados na Unidade de Reumatologia Pediátrica do Instituto da Criança (ICr) e Divisão de Odontologia do Instituto Central - Hospital das Clínicas (HC) - Faculdade de Medicina da Universidade de São Paulo (FMUSP) evidenciaram maior envolvimento da ATM e piores índices de saúde bucal nos pacientes com AlJ em relação ao grupo controle pareado por idade. Os pacientes que apresentaram maior envolvimento articular dos membros superiores (mais que três articulações acometidas) tiveram uma precária higiene bucal (Savioli et al., 2004; Savioli et al., 2000). O uso de corticosteróides e imunossupressores e/ou atividade clínico-laboratorial mantida do LESJ podem determinar: erupção dentária tardia, alteração do desenvolvimento das raízes dentárias e doença periodontal (Carrel et al., 1990; Story-Lewis et al., 1987).

O conhecimento das alterações decorrentes do LESJ e, a avaliação precoce e rotineira do sistema mastigatório e da saúde bucal dos pacientes com esta doença são necessários a fim de identificar fatores de risco para a ocorrência destas alterações, bem como estabelecer planos de tratamento que minimizem a morbidade potencial associada a esta doença proporcionando melhora na qualidade de vida destas crianças. A ausência de estudos na literatura médica avaliando as características orofaciais nos pacientes com LESJ estimulou a realização do presente estudo. 


\section{OBJETIVOS}


1. Avaliar o comprometimento orofacial nos pacientes com LESJ e grupo controle.

2. Avaliar possíveis associações entre o comprometimento orofacial e manifestações clínicas, exames laboratoriais e terapias da doença. 


\section{MÉTODOS}


Um estudo transversal foi realizado durante os meses de março de 2004 a julho de 2005. Foram avaliados 52 pacientes com diagnóstico de LES juvenil, segundo os critérios revisados pelo ACR (Hochberg, 1997) (ANEXO A), atendidos consecutivamente na Unidade de Reumatologia Pediátrica do ICr-HC-FMUSP. A admissão no estudo foi realizada após a assinatura de Termo de Consentimento Livre e Esclarecido (TCLE) para pacientes (ANEXO B). O estudo foi aprovado pela Comissão de Ética em Pesquisa do HC-FMUSP (CAPPesq 014/03).

Os pacientes com LESJ e as crianças e adolescentes do grupo controle que apresentaram plaquetopenia, neutropenia, comorbidades locais ou outras doenças sistêmicas com repercussões dentárias ou articulares foram excluídos. Quatro pacientes com LESJ foram excluídos: três em tratamento ortodôntico e um com micrognatia congênita. O número total de pacientes com LESJ foi 48.

O grupo controle saudável foi composto de 48 crianças e adolescentes saudáveis e pareados por idade, sexo e classe sócioeconômica (Almeida et al., 1991) (ANEXO C), que foram avaliados na consulta admissional na Divisão de Odontologia do Instituto Central do HCFMUSP. Para a participação no estudo, houve também necessidade da assinatura do TCLE para o grupo controle (ANEXO D). 
A pesquisa incluiu uma avaliação de dados sócio-demográficos (idade atual, tempo de duração da doença e sexo), manifestações clínicas, exames laboratoriais e terapias da doença, assim como uma avaliação orofacial (ANEXO E).

A determinação das características clínicas da doença, no momento da avaliação orofacial, incluiu: avaliação do comprometimento renal (hematúria, leucocitúria, cilindrúria, proteinúria, hipertensão arterial e/ou biópsia renal com nefrite lúpica, segundo Mc Curdy et al. (1992), comprometimento mucocutâneo (eritema malar, úlcera oral e/ou vasculite), artrite, serosite (pleurite e/ou pericardite), comprometimento neurológico e hematológico (anemia hemolítica, leucopenia e/ou plaquetopenia). Os exames laboratoriais realizados foram: níveis séricos do complemento (complemento total e das frações C3 e C4) e anticorpo anti-DNA nativo ou dupla hélice (avaliado pela imunoflurescência indireta, usando como substrato a Crithidia luciliae). Em pelo menos duas mensurações, os anticorpos anti-fosfolípides foram determinados: anticorpo anti-cardiolipina [utilizando-se a técnica de "Enzime-linked immunosorbent assay" (ELISA) com kit comercial Hemagen anticardiolipina $\left.{ }^{\circledR}\right]$ e anticorpo anti-coagulante lúpico detectado através de três métodos: tempo de tromboplastina parcial ativada, teste do veneno de víbora de Russell diluído e teste do tempo de coagulação de kaolin (Campos et al., 2003).

Para a quantificação da atividade da doença foi utilizado o escore denominado "Systemic Lupus Erythematosus Disease Activity Index" 
(SLEDAI) (Bombardier et al., 1992) (ANEXO F). Valor do SLEDAI maior ou igual a quatro foi considerado, arbitrariamente, como doença ativa.

O dano cumulativo do LESJ foi avaliado segundo o "Systemic Lupus International Collaborating Clinics/ACR Damage Index (SLICC/ACR-DI)" (Gladman et al., 1996) (ANEXO G). Valor do SLICC/ACR-DI maior ou igual a um foi considerado como algum dano cumulativo do LESJ.

O padrão de atividade ou curso da doença, definido por Barr et al. (1999), foi dividido em três tipos: remissivo (caracterizado por doença sem atividade por pelo menos um ano), remissivo-recidivante [caracterizado por períodos de atividade da doença intercalados por períodos de doença inativa (durante um ano em duas ou mais consultas)] e crônico ativo (no qual a doença persiste ativa por pelo menos um ano).

A atividade do LESJ, dano cumulativo, curso da doença e tratamento medicamentoso recebido (corticosteróide, antimalárico, talidomida, metotrexato, ciclosporina, pulsoterapia endovenosa com ciclofosfamida, azatioprina e/ou micofenolato mofetil) foram determinados na mesma ocasião da avaliação orofacial. As doses de todos os corticosteróides utilizados (metilprednisolona, prednisona e prednisolona) foram transformadas em gramas de prednisona através do cálculo de equivalência entre as drogas. A dose cumulativa total de prednisona foi somada durante todo o tratamento do LESJ.

A avaliação orofacial foi realizada por uma única odontologista pediátrica da Divisão de Odontologia do Instituto Central do HC-FMUSP e incluiu um questionário de anamnese, avaliação clínica (periodonto, dentes, 
perfil facial, relação molar e ATM) e radiografia panorâmica de face. A presença de dor orofacial foi também caracterizada, através do questionário de anamnese, com ênfase em: duração, freqüência, tipo, localização, intensidade, fatores de modulação da dor e tratamentos realizados (Siqueira et al., 2003).

Avaliações dentária e gengival foram determinadas pelos índices de placa (IP) (Ainamo et al., 1975) e de sangramento gengival (IS) (O'Leary, 1967). O IP foi utilizado para avaliar a condição de higiene oral. Este índice foi calculado pelo número de superfícies dentárias coradas por pastilhas evidenciadoras de placa bacteriana multiplicado por 100 e dividido pelo número total de superfícies. Inflamação gengival (gengivite) foi avaliada pelo IS, determinado pelo número de superfícies sangrantes após uso de sonda periodontal, multiplicado por 100 e dividido pelo número total de superfícies. Também foi realizada uma avaliação dentária do número de dentes cariados, perdidos e obturados (índice CPO-D) (WHO, 1997).

O perfil facial foi determinado pela análise da face diferindo três padrões: côncavo, convexo ou reto (Savioli et al., 2004). A relação molar foi determinada de acordo com a classificação de Angle, considerando a posição do primeiro molar superior em relação ao primeiro molar inferior (English et al., 2002).

A avaliação clínica da ATM foi realizada pelo índice de Helkimo (Helkimo, 1974) que inclui o índice de disfunção mandibular clínica (IDC) e o índice de mobilidade mandibular (IMM). O IDC avalia cinco sinais clínicos de disfunção mandibular [dor a palpação dos músculos mastigatórios, dor a 
palpação da ATM, dor aos movimentos mandibulares, comprometimento funcional da ATM (desvio ou ruído articular) e IMM alterado], com escores em cada um destes variando de 0 a 5 conforme a gravidade, sendo o resultado final a somatória destes escores (IDC máximo de 25). Um IDC com escore 0 denota ausência de disfunção clínica da ATM, 1-4 disfunção leve, 5-9 moderada e 10-25 disfunção grave. O IMM avalia a amplitude de quatro movimentos mandibulares [abertura da boca interincisal máxima (normal $\geq 40 \mathrm{~mm}$ ), lateralidade direita e esquerda (normal $\geq 7 \mathrm{~mm}$ ) e protrusão (normal $>7 \mathrm{~mm})$ ], com escores em cada um destes variando de 0 a 5 , dependendo da gravidade, sendo o resultado final a somatória dos escores (IMM máximo de 20). Um IMM de 0 denota mobilidade mandibular normal, 1-4 mobilidade levemente comprometida e de 5-20 mobilidade gravemente comprometida.

A análise radiográfica foi determinada através da radiografia panorâmica da face realizada no Serviço de Radiologia HC-FMUSP que avaliou esqueleto facial, dentes, periodonto e ATM. As alterações dos côndilos mandibulares foram classificadas em quatro graus: grau 0 (ausência de anormalidades radiográficas), grau 1 (irregularidade na borda condilar com discretas erosões), grau 2 (aplainamento do côndilo) e grau 3 (destruição total do côndilo) (Pedersen et al., 2001). Nos pacientes que apresentaram radiografia panorâmica de face compatível com os graus 2 e 3, foi também realizada tomografia computadorizada (aparelho Light Speed-Multislice - GE, WI) de ATM para melhor avaliação da lesão radiográfica. Esta avaliação foi feita por três examinadores distintos e especialistas em ATM e/ou radiologistas. 


\subsection{ANÁLISE ESTATÍSTICA}

Testes paramétricos e não paramétricos foram realizados para avaliar a distribuição dos valores das variáveis ou da variabilidade das medidas. $\mathrm{O}$ teste "t" não pareado para duas amostras independentes foi utilizado para comparar a média da idade dos pacientes com LESJ e grupo controle e o teste exato de Fischer para comparar o sexo nestes grupos. $O$ teste de Mann-Whitney foi utilizado para comparar os índices e características orofaciais (CPO-D, IP, IS, IDC, IMM, oclusão e perfil facial) entre os dois grupos avaliados. Este teste também comparou as características orofaciais entre os pacientes com LESJ de acordo a presença de: atividade do LESJ (SLEDAI $\geq 4$ ), dano cumulativo da doença (SLICC-ACR-DI $\geq 1$ ) e uso atual de um ou mais imunossupressores. O teste qui-quadrado foi utilizado para comparar presença de queixas orofaciais, características do IDC (dor a palpação dos músculos mastigatórios, dor a palpação da ATM, dor aos movimentos mandibulares, comprometimento funcional da ATM e mobilidade mandibular alterada) e IMM (abertura máxima da boca, lateralidade direita e esquerda e protrusão) nos dois grupos estudados. O coeficiente de correlação de Pearson foi utilizado para estabelecer uma correlação linear entre: tempo de doença e IP, tempo de doença e IS, entre IP e IS, assim como entre dose cumulativa de prednisona e IP e IS. Em todos os testes estatísticos, o nível de significância foi de $5 \%(p<0,05)$. 


\section{RESULTADOS}


Os dois grupos foram igualmente compostos por 48 pacientes e foram homogêneos com relação à faixa etária, distribuição por gênero e classe sócio-econômica. A idade atual dos pacientes com LESJ variou de 87 a 218 meses (média de 161,9 $\pm 38,4$ ) e do grupo controle variou de 78 a 254 meses (média de 154,4 $\pm 45,8$ ) (Tabela 1).

A única queixa orofacial relatada pelos pacientes foi odontalgia. Associação estatística não foi encontrada nos dois grupos com relação a presença de odontalgia. Oito pacientes com o LESJ $(16,7 \%)$ referiam odontalgia versus nove $(18,7 \%)$ do grupo controle $(p=0,789)$.

Com relação ao índice CPO-D não houve diferença estatística entre os pacientes com LESJ e do grupo controle. Por sua vez, as medianas dos IP e IS nos pacientes com LESJ foram superiores em relação ao grupo controle (Tabela 2). 
Tabela 1 - Características demográficas dos pacientes com lúpus eritematoso sistêmico juvenil (LESJ) e grupo controle submetidos à avaliação orofacial

\begin{tabular}{lccc}
\hline Características demográficas & LESJ $(\mathbf{n}=\mathbf{4 8})$ & Controle $(\mathbf{n}=\mathbf{4 8})$ & $\mathbf{p}$ \\
\hline $\begin{array}{l}\text { Idade atual em meses } \\
\text { (média } \pm \text { DP) }\end{array}$ & $161,9 \pm 38,4$ & $154,4 \pm 45,8$ & 0,384 \\
Sexo feminino (\%) & 85,40 & 66,70 & 0,054 \\
Classe sócio-econômica C (\%) & 54,20 & 60,40 & 0,26 \\
\hline
\end{tabular}

DP - desvio-padrão

Tabela 2 - Distribuição dos índices CPO-D, de placa e sangramento gengival nos pacientes com lúpus eritematoso sistêmico juvenil (LESJ) e grupo controle

\begin{tabular}{lccc}
\hline Índices & LESJ $(\mathbf{n}=\mathbf{4 8})$ & Controle $(\mathbf{n = 4 8})$ & $\mathbf{p}$ \\
\hline CPO-D mediana (variação) & $4,0(0-14)$ & $4,0(0-15)$ & 0,746 \\
IP mediana (variação) & $61,50(0-100)$ & $38,10(5,8-100)$ & 0,003 \\
IS mediana (variação) & $26,0(0-74,1)$ & $15,95(0-51,7)$ & 0,014
\end{tabular}

CPO-D - índice de número de dentes cariados, perdidos e obturados, IP- índice de placa, IS - índice de sangramento gengival. 
A relação molar classe I foi a mais freqüente nos dois grupos, não havendo diferença significativa entre ambos. $O$ perfil reto foi o mais encontrado nos dois grupos e também não houve diferença significativa entre eles (Tabela 3).

Tabela 3 - Características da relação molar e perfil facial nos pacientes com lúpus eritematoso sistêmico juvenil (LESJ) e grupo controle

\begin{tabular}{lccc}
\hline Características orofaciais & $\begin{array}{c}\text { LESJ } \\
(\mathbf{n = 4 8})\end{array}$ & $\begin{array}{c}\text { Controle } \\
(\mathbf{n = 4 8 )}\end{array}$ & $\mathbf{p}$ \\
\hline $\begin{array}{l}\text { Relação molar } \\
\text { Mediana (variação) }\end{array}$ & $\mathbf{1 , 0}(\mathbf{1 - 3 )}$ & $\mathbf{1 , 0}(\mathbf{1 - 3 )}$ & $\mathbf{0 , 4 9 1}$ \\
Classe I n (\%) & $35(72,92)$ & $32(66,67)$ & \\
Classe II n (\%) & $7(14,58)$ & $8(16,67)$ & \\
Classe III n (\%) & $6(12,50)$ & $8(16,67)$ & $\mathbf{0 , 3 2 1}$ \\
Perfil facial & & $\mathbf{1}$ & \\
Mediana (variação) & $\mathbf{1 , 0}(\mathbf{1 - 3})$ & $43(89,58)$ & \\
Reto n (\%) & $39(81,25)$ & $1(2,08)$ & \\
Côncavo n (\%) & $7(14,58)$ & $4(8,33)$ & \\
Convexo n (\%) & $2(4,17)$ &
\end{tabular}

Entre os pacientes com LESJ e o grupo controle observou-se diferença significativa com relação ao índice de Helkimo. Os pacientes com LESJ apresentaram uma maior freqüência de IDC grave em relação ao grupo controle com diferença estatística significativa, o mesmo ocorreu com IMM grave (Tabela 4). Com relação às características do índice de disfunção clínica de Helkimo, apenas o comprometimento funcional da ATM foi mais 
freqüente nos pacientes com LESJ versus grupo controle, com diferença estatisticamente significativa (Tabela 5).

Tabela 4 - Características do índice de Helkimo nos pacientes com lúpus eritematoso sistêmico juvenil (LESJ) e grupo controle

\begin{tabular}{|c|c|c|c|}
\hline Índice de Helkimo & $\begin{array}{l}\text { LESJ } \\
(n=48)\end{array}$ & $\begin{array}{l}\text { Controle } \\
(n=48)\end{array}$ & p \\
\hline \multicolumn{4}{|c|}{ Índice de disfunção clínica } \\
\hline Mediana (variação) & $1,0(0-3)$ & $1,0(0-2)$ & 0,002 \\
\hline Grave n (\%) & $4(8,33)$ & 0 & \\
\hline Moderada n (\%) & $15(31,25)$ & $7(14,58)$ & \\
\hline Leve n (\%) & $23(47,92)$ & $27(56,25)$ & \\
\hline Normal n (\%) & $6(12,50)$ & $14(29,17)$ & \\
\hline \multicolumn{4}{|c|}{ Índice de mobilidade mandibular } \\
\hline Mediana (variação) & $1,0(0-2)$ & $0(0-1)$ & 0,025 \\
\hline Grave n (\%) & $3(6,25)$ & 0 & \\
\hline Leve n (\%) & $19(39,58)$ & $19(39,58)$ & \\
\hline Normal n (\%) & $26(54,17)$ & $29(60,42)$ & \\
\hline
\end{tabular}

Tabela 5 - Distribuição da presença do índice de disfunção clínica de Helkimo nos pacientes com lúpus eritematoso sistêmico juvenil (LESJ) e grupo controle

\begin{tabular}{lccc}
\hline Índice de disfunção clínica & $\begin{array}{c}\text { LESJ } \\
(\mathbf{n = 4 8 )}\end{array}$ & $\begin{array}{c}\text { Controle } \\
(\mathbf{n = 4 8 )}\end{array}$ & p \\
\hline Dor a palpação dos músculos mastigatórios n (\%) & $28(58,33)$ & $22(45,83)$ & 0,220 \\
Dor a palpação da ATM n (\%) & $7(14,58)$ & $3(6,25)$ & 0,181 \\
Dor aos movimentos mandibulares n (\%) & $1(2,08)$ & $2(4,16)$ & 0,557 \\
Comprometimento funcional da ATM n (\%) & $11(22,91)$ & $4(8,33)$ & 0,049 \\
\hline
\end{tabular}


No índice de mobilidade mandibular, apenas as reduções das lateralidades direita e esquerda mandibulares foram mais freqüentes nos pacientes com LESJ versus controles normais (Tabela 6).

Tabela 6 - Distribuição da amplitude inadequada do índice de mobilidade mandibular de Helkimo nos pacientes com lúpus eritematoso sistêmico juvenil (LESJ) e grupo controle

\begin{tabular}{|c|c|c|c|}
\hline Índice de mobilidade mandibular & $\begin{array}{l}\text { LESJ } \\
(n=48)\end{array}$ & $\begin{array}{c}\text { Controle } \\
(n=48)\end{array}$ & $\mathbf{p}$ \\
\hline Abertura da boca $<40 \mathrm{~mm} \mathrm{n} \mathrm{( \% )}$ & $5(10,41)$ & $1(2,08)$ & 0,092 \\
\hline Lateralidade direita $<7 \mathrm{~mm} \mathrm{n}(\%)$ & $4(8,33)$ & $0(0)$ & 0,041 \\
\hline Lateralidade esquerda $<7 \mathrm{~mm} n(\%)$ & $9(18,75)$ & $0(0)$ & 0,02 \\
\hline Protrusão $\leq 6 \mathrm{~mm} \mathrm{n} \mathrm{( \% )}$ & $23(47,91)$ & $20(41,66)$ & 0,538 \\
\hline
\end{tabular}

Entre os 48 pacientes com LESJ, 26 realizaram a radiografia panorâmica de mandíbula. Destes, apenas dois $(7,69 \%)$ pacientes apresentaram alterações radiográficas nos côndilos mandibulares compatíveis com Grau 2 ou 3. Estes dois pacientes realizaram tomografia computadorizada que revelou: redução do espaço articular bilateralmente, irregularidade e alterações erosivas dos platôs articulares com aplainamento articular sugestivo de necrose avascular da ATM. Estes pacientes não referiam queixas orofaciais e apresentavam índice de Helkimo levemente comprometido. Um paciente apresentava IDC escore 1 (dor à palpação muscular) e IMM escore 1 (lateralidade esquerda $<7 \mathrm{~mm}$ ). O outro paciente apresentava IDC escore 1 (desvio da ATM > 2mm) e IMM escore 1 (abertura 
máxima da boca $<40 \mathrm{~mm}$ ). Entre os controles, 28 pacientes realizaram as radiografias e não apresentaram Grau 2 ou $3(p=0,22)$.

\subsection{CARACTERÍSTICAS OROFACIAIS DOS PACIENTES COM LESJ}

O tempo de duração do LESJ variou de 4 a 104 meses (média 38,3 \pm $28,7)$. No momento da realização do estudo, o escore do SLEDAI variou de 0 a 21 (média 4,1 $\pm 5,1$ ), 23 pacientes estavam em atividade da doença $($ SLEDAI $\geq 4)$ (Tabela 7$)$ e destes sete apresentavam SLEDAI $\geq 8$. Não houve correlação linear estatística entre SLEDAI e IP $(p=0,568)$, assim como entre SLEDAI e IS $(p=0,862)$.

O escore do SLICC-ACR-DI e o curso da doença foram avaliados em 44 pacientes que apresentaram tempo de doença acima de seis meses. $O$ SLICC-ACR-DI variou de 0 a 4 (média $1 \pm 1$ ) e 19 pacientes apresentavam algum dano cumulativo da doença (SLICC-ACR-DI $\geq 1$ ) (Tabela 8). O curso da doença foi crônico-ativo em 30 (68\%), remissivo-recidivante em 13 (30\%) e remissivo em um (2\%). No momento da avaliação orofacial nenhum dos pacientes apresentava plaquetopenia, neutropenia, assim como queixas de xerostomia e xeroftalmia. 
Tabela 7 - Características orofaciais dos pacientes com lúpus eritematoso sistêmico juvenil (LESJ) de acordo com a atividade da doença

\begin{tabular}{lccc}
\hline Características orofaciais & $\begin{array}{c}\text { SLEDAI }<4 \\
(\mathbf{n}=\mathbf{2 5})\end{array}$ & $\begin{array}{c}\text { SLEDAI } \geq \mathbf{4} \\
(\mathbf{n = 2 3})\end{array}$ & $\mathbf{p}$ \\
\hline CPO-D mediana (variação) & $4,0(0-11)$ & $5,0(0-14)$ & 0,740 \\
IP mediana (variação) & $60(10,4-100)$ & $64,7(0-100)$ & 0,512 \\
IS mediana (variação) & $28,6(0-74,1)$ & $19,8(0-73,2)$ & 0,483 \\
IDC mediana (variação) & $1,0(0-3)$ & $1,0(0-3)$ & 0,435 \\
IMM mediana (variação) & $1,0(0-2)$ & $1,0(0-2)$ & 0,420 \\
\hline
\end{tabular}

CPO-D - índice de número de dentes cariados, perdidos e obturados, IP- índice de placa, IS-índice de sangramento gengival, IDC- índice de disfunção clínica, IMM-índice de mobilidade mandibular, SLEDAI- Systemic Lupus Erythematosus Disease Activity Index.

Tabela 8 - Características orofaciais dos pacientes com lúpus eritematoso sistêmico juvenil (LESJ) de acordo com o dano cumulativo da doença

\begin{tabular}{lccc}
\hline Características orofaciais & $\begin{array}{c}\text { SLICC/ACR-DI }=\mathbf{0} \\
\mathbf{( n = 2 5 )}\end{array}$ & $\begin{array}{c}\text { SLICC/ACR-DI } \geq \mathbf{1} \\
(\mathbf{n = 1 9 )}\end{array}$ & $\mathbf{p}$ \\
\hline IP mediana (variação) & $51,8(10,4-100,0)$ & $70,9(22,3-100,0)$ & 0,269 \\
IS mediana (variação) & $25,0(3,6-73,2)$ & $31,4(0-74,1)$ & 0,258 \\
IDC mediana (variação) & $1,0(0-3)$ & $1,0(0-3)$ & 0,786 \\
IMM mediana (variação) & $1,0(0-2)$ & $1,0(0-2)$ & 0,433 \\
\hline
\end{tabular}

IP- índice de placa, IS-índice de sangramento gengival, IDC- índice de disfunção clínica, IMM-índice de mobilidade mandibular, SLICC/ACR-DI- Systemic Lupus International Collaborating Clinics/ACR Damage Index. 
Uma correlação estatística entre tempo de doença e IP não foi observada ( $p=0,269 ; R=0,02)$ (Figura 2). Entretanto, uma correlação linear estatística foi evidenciada entre tempo de doença e IS, porém com uma fraca correlação ( $p=0,017 ; R=0,11)$ (Figura 3); o mesmo ocorreu entre IP e IS nos pacientes com LESJ ( $p=0,011 ; R=0,13)$ (Figura 4).

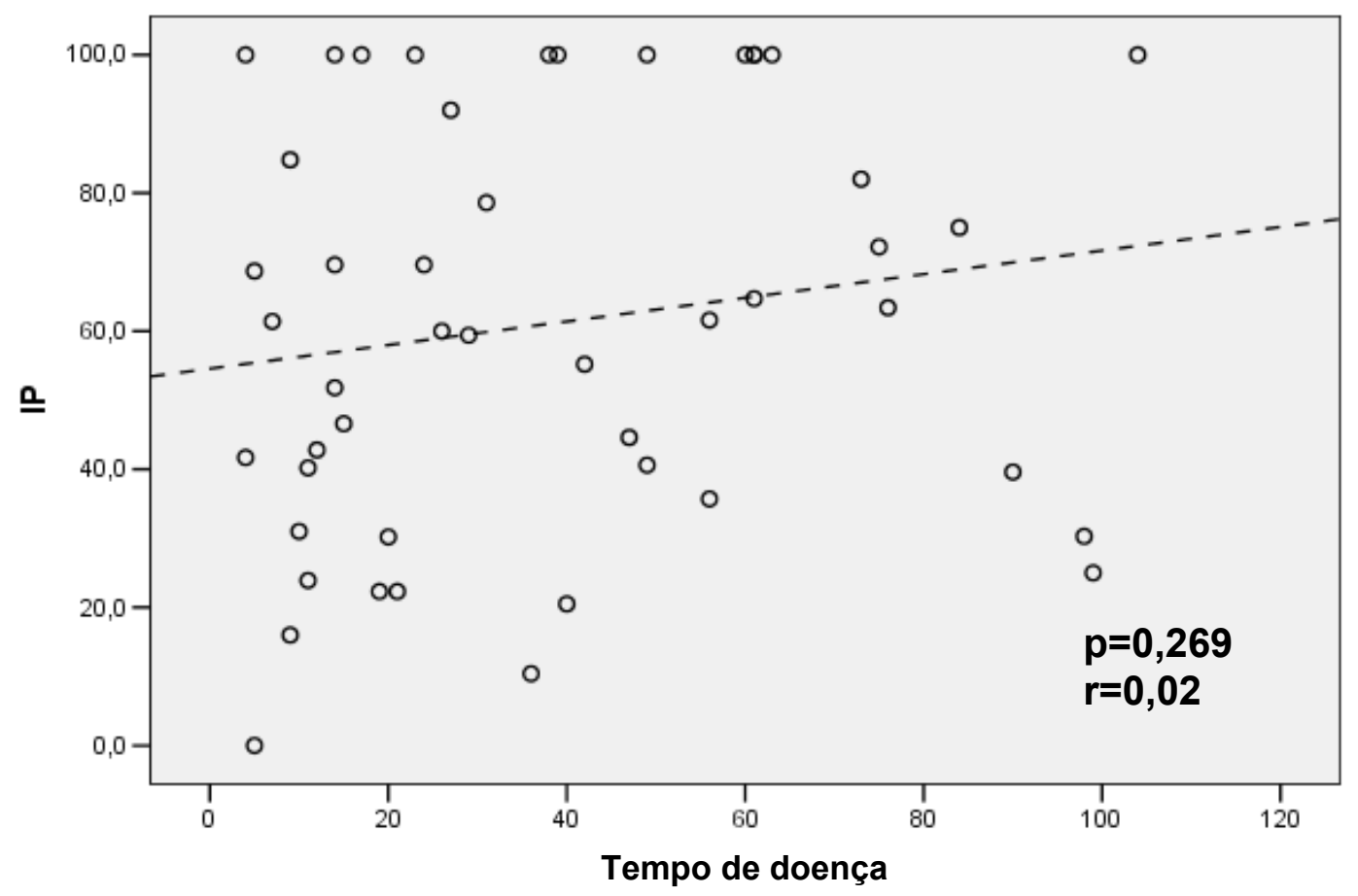

Figura 2 - Correlação entre tempo de doença e índice de placa nos pacientes com lúpus eritematoso sistêmico juvenil (LESJ) 


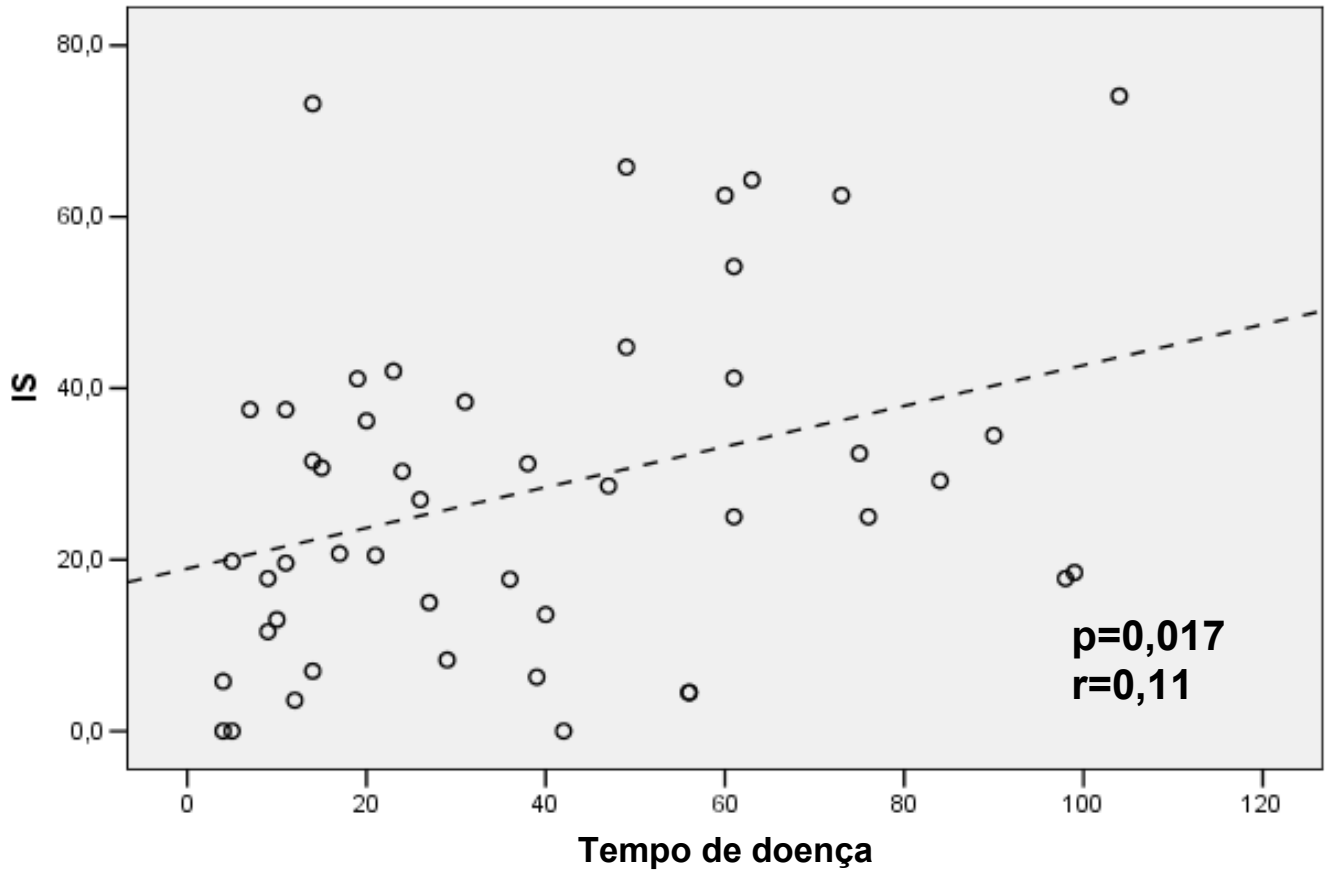

Figura 3 - Correlação entre tempo de doença e índice de sangramento gengival nos pacientes com lúpus eritematoso sistêmico juvenil (LESJ)

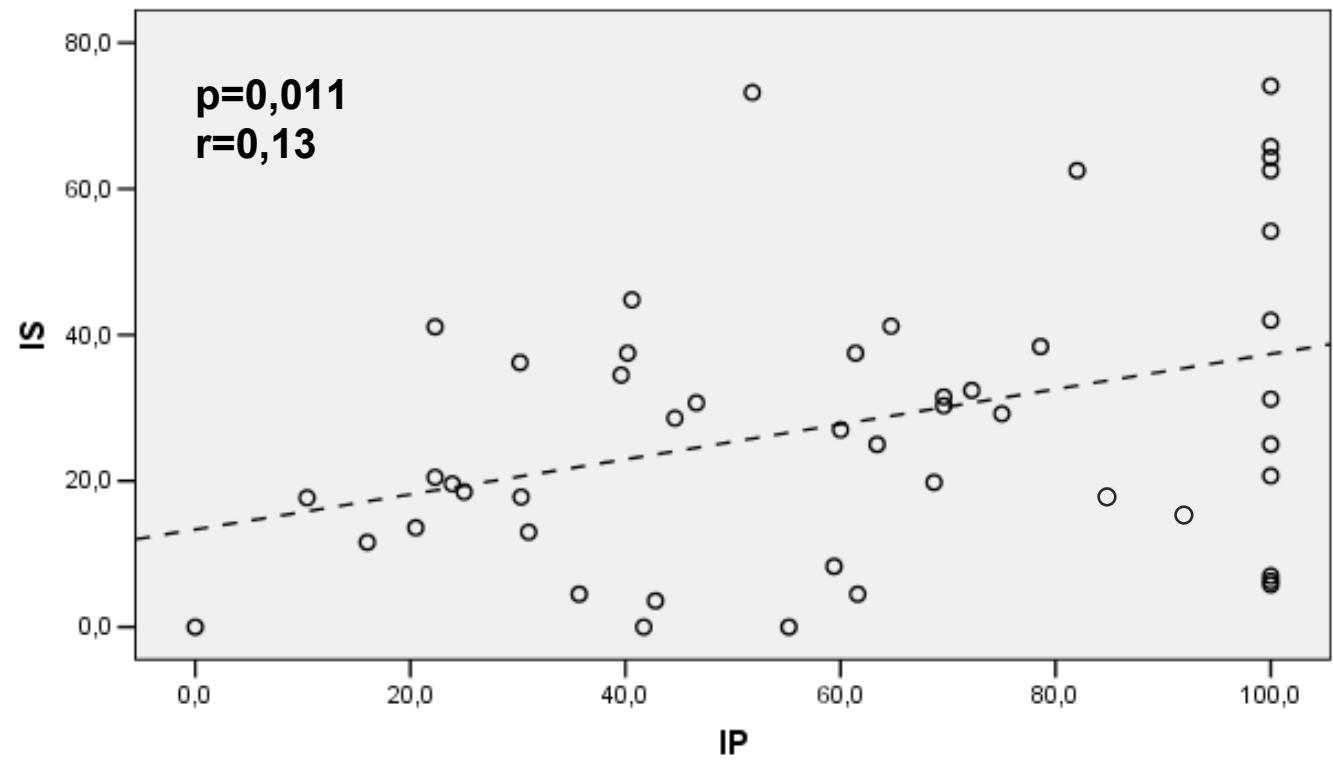

Figura 4 - Correlação entre índice de placa e índice de sangramento gengival nos pacientes com lúpus eritematoso sistêmico juvenil (LESJ) 
No período de avaliação, apenas um paciente não estava recebendo medicação. Corticosteróides foram utilizados em 47, antimaláricos (cloroquina ou hidroxicloroquina) em 43 e imunossupressores em 23 (pulsoterapia com ciclofosfamida endovenosa em 12, metotrexato em seis, azatioprina em cinco, ciclosporina em dois e micofenolato mofetil em um). Uma correlação linear estatística foi estabelecida entre dose cumulativa de prednisona e IP $(p=0,010, r=0,385)$ (Figura 5), assim como entre dose cumulativa de prednisona e IS $(p=0,001, r=0,471)$ (Figura 6).

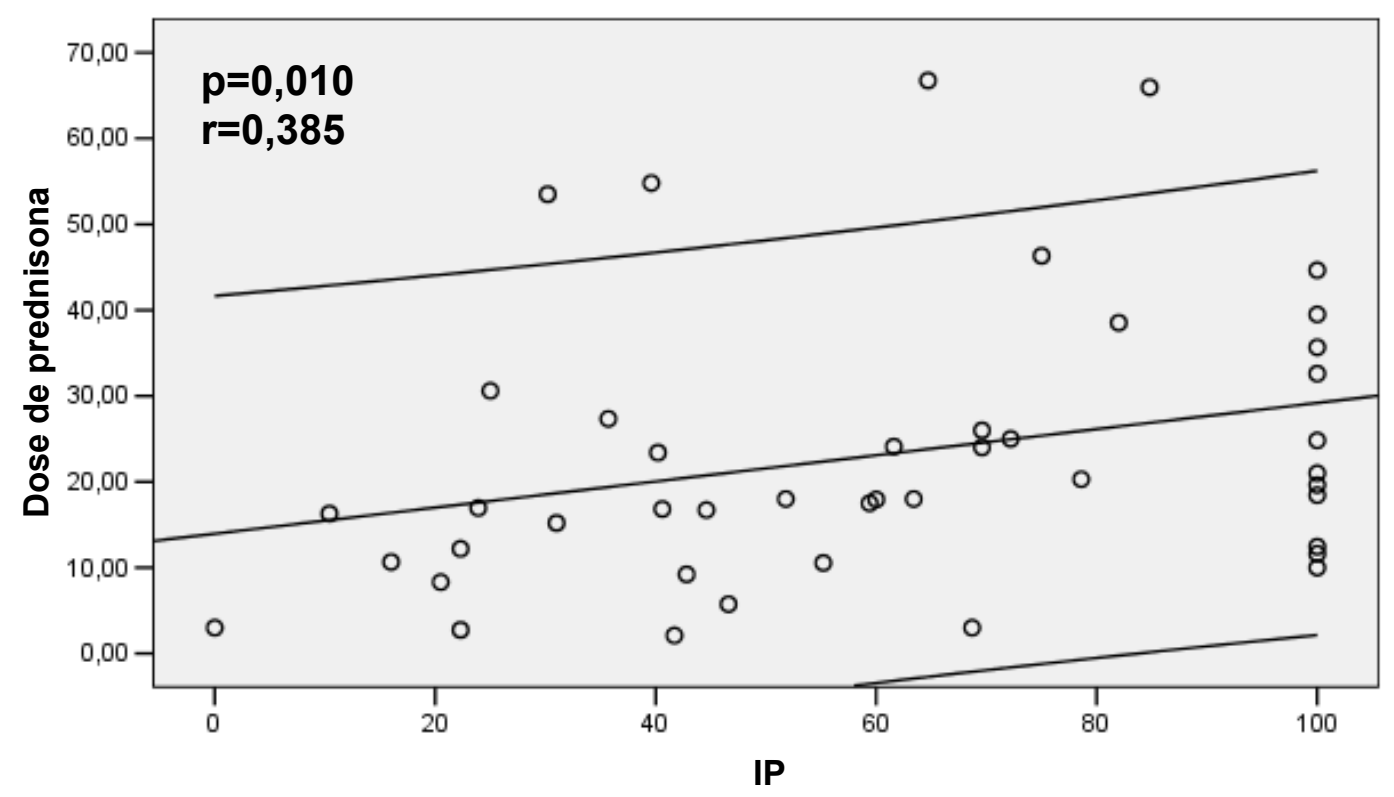

Figura 5 - Correlação entre dose de prednisona e índice de placa nos pacientes com lúpus eritematoso sistêmico juvenil (LESJ) 


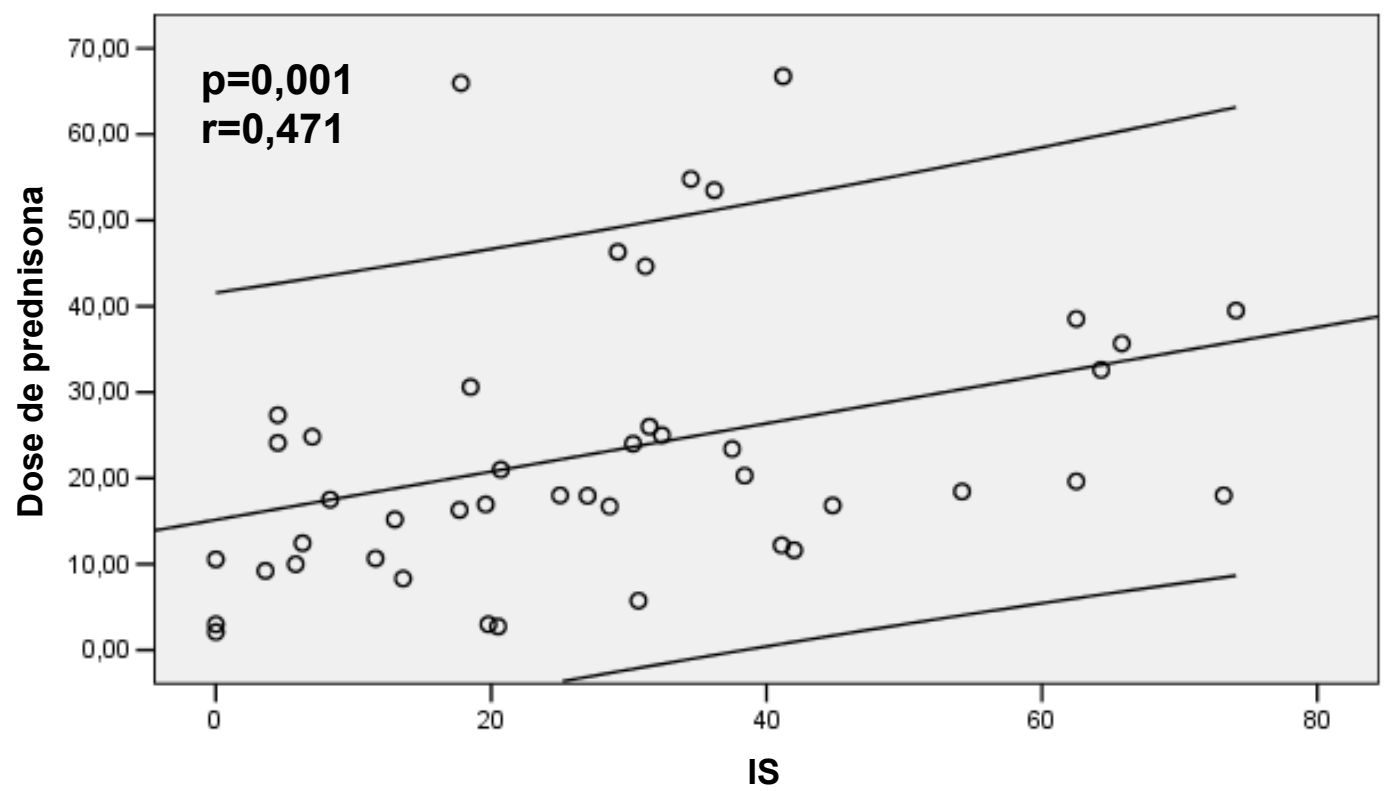

Figura 6 - Correlação entre dose de prednisona e índice de sangramento gengival nos pacientes com lúpus eritematoso sistêmico juvenil (LESJ) 
Com relação às características orofaciais nos pacientes com LESJ que utilizaram imunossupressores, apenas o IMM evidenciou associação estatística. A mediana do IMM foi maior nos pacientes com LESJ em uso de um ou mais imunossupressores em relação aos que não utilizaram estas drogas (Tabela 9).

Tabela 9 - Características orofaciais dos pacientes com lúpus eritematoso sistêmico juvenil (LESJ) com relação a utilização de imunossupressores

\begin{tabular}{lccc}
\hline Características orofaciais & $\begin{array}{c}\text { LESJ com IM } \\
(\mathbf{n = 2 3 )}\end{array}$ & $\begin{array}{c}\text { LESJ sem IM } \\
(\mathbf{n = 2 5})\end{array}$ & $\mathbf{p}$ \\
\hline IP & 64,7 & 60,0 & 0,693 \\
Mediana (variação) & $(10,4-100,0)$ & $(0-100,0)$ & \\
IS & 28,6 & 19,6 & 0,672 \\
Mediana (variação) & $(0-64,3)$ & $(0-74,1)$ & \\
IDC & 1,0 & 1,0 & 0,185 \\
Mediana (variação) & $(1-3)$ & $(0-3)$ & \\
IMM & 1,0 & 0 & 0 \\
Mediana (variação) & $(1-2)$ & $(0-2)$ & \\
\hline
\end{tabular}

IM- imunossupressor, IP- índice de placa, IS-índice de sangramento gengival, IDC- índice de disfunção clínica, IS-índice de mobilidade mandibular.

No momento da avaliação orofacial dos pacientes com LESJ não houve diferença estatística entre as características orofaciais avaliadas (IP, IS, IDC, IMM) e as manifestações clínicas da doença (comprometimento renal, comprometimento mucocutâneo, serosite, comprometimento neurológico e hematológico). Assim como, não houve diferença estatística entre a presença dos anticorpos anti-fosfolípides (anti-cardiolipina lgG, IgM ou anti-coagulante lúpico) e às mesmas características orofaciais avaliadas. 
5. DISCUSSÃO 
As doenças reumatológicas pediátricas são raras e apresentam alto impacto físico, mental, econômico e social nos pacientes e seus familiares. Apesar do LESJ ser uma doença crônica com períodos de atividade e remissão, o prognóstico e sobrevida destes pacientes vem melhorando progressivamente nas últimas duas décadas, sendo importante a avaliação do comprometimento orofacial. Este acometimento pode alterar a qualidade de vida das crianças e adolescentes com LESJ. Dor orofacial, disfunção da ATM e infecções orais podem reduzir rendimento escolar, produtividade no trabalho e prejudicar as relações sociais (Hollister et al., 1993).

A ausência de trabalhos publicados na literatura sobre as reais condições de saúde bucal e disfunção da ATM nos pacientes com LESJ motivou a realização do presente estudo.

Este foi um estudo que incluiu uma população homogênea para faixa etária, sexo e classe sócio-econômica nos pacientes com LESJ e controles. Nesta pesquisa, os pacientes com LESJ não apresentaram síndrome de Sjögren ou envolvimento hematológico que poderiam alterar os índices de saúde bucal.

Doença dentária e gengival não tratadas podem ser fatores de risco significativo, como porta de entrada para o desencadeamento de infecção sistêmica, especialmente nos pacientes imunodeprimidos submetidos a 
tratamento com uso crônico de corticosteróides e imunossupressores (Foster et al., 2005; Welbury et al. , 2003).

Gengivite afeta mais de $70 \%$ das crianças eutróficas maiores de sete anos (Stamm, 1986). Por sua vez, a gengivite crônica é a infecção periodontal mais prevalente entre crianças e adolescentes (Oh et al., 2002). Bimstein (1991) relatou a importância da prevenção, diagnóstico e tratamento precoces das doenças periodontais nas crianças e adolescentes. Nesta faixa etária pode haver uma alta prevalência e gravidade das doenças periodontais, assim como doença periodontal incipiente na faixa etária pediátrica poderá ocasionar periodontites graves nos adultos. Doença periodontal está associada com doenças sistêmicas, tais como: diabetes mellitus insulino-dependente, síndrome de Down, leucemia, histiocitose das células de Langerhans e em adultos com LES. Populações de risco devem ser identificadas e inclusas em um programa especial de prevenção e tratamento (Bimstein, 1991; Armitage, 1999; Oh et al., 2002).

Apesar da homogeneidade do índice CPO-D nos dois grupos estudados houve uma alta prevalência deste índice nestes grupos, com mediana de quatro em ambos. A Organização Mundial de Saúde preconiza uma adequada saúde bucal com índice de CPO-D inferior a três. Mundialmente, setenta por cento dos países alcançaram esta meta aos 12 anos de idade (Nishi et al., 2002; WHO 2004).

Diversos estudos nas últimas décadas apontaram uma expressiva redução na prevalência de cárie dentária na maioria dos países desenvolvidos. No entanto, em certas cidades do Brasil não houve essa diminuição devido a 
ausência de fluoretação da água de abastecimento, a falta de acesso a programas preventivos e baixo nível sócio-econômico-cultural (Cardoso et al., 2003). O processo de formação das cáries dentárias é multifatorial. Os fatores de risco mais relevantes são: baixa ingestão adequada de flúor, hábitos alimentares inadequados, uso de medicamentos açucarados e precária higiene oral. O flúor protege os dentes contra as cáries desde o seu desenvolvimento até os dentes já erupcionados (Welbury et al., 2003).

Os IP e IS foram significativamente mais elevados nos pacientes com LESJ em relação ao grupo controle, demonstrando uma pior higiene oral nestes pacientes. A higiene oral prejudicada, com redução da escovação dentária e uso do fio dental, pode ser explicada por ser o LESJ uma doença grave e sistêmica, com maior preocupação em relação ao horário das medicações e uso de fotoprotetores.

A infecção é uma dos principais causas de morbimortalidade nos pacientes com LESJ. A presença de alterações imunológicas próprias da doença, tais como disfunção de fagócitos, linfopenia, asplenia funcional, assim como diminuição de: citocinas, imunoglobulinas e frações do complemento predispõem os pacientes com LESJ a desenvolverem infecções (Oh et al., 1993; Raj et al., 2002).

Por sua vez, estes pacientes recebem corticosteróides que aumentam o apetite, com refeições freqüentes, abundantes e hipercalóricas, que necessitariam um maior cuidado de sua saúde bucal (Souza et al., 2005; Welbury et al., 2003). O uso crônico de corticosteróides também predispõe a infecções, como a dentária. Por sua vez, estas drogas podem mascarar 
alguns sinais clínicos de infecção como resultado da sua ação antiinflamatória e imunossupressora. Neste estudo, os pacientes que receberam uma maior dose cumulativa de corticosteróides apresentaram maiores valores de IP e IS, indicando piores condições de higiene oral nos pacientes mais graves. Além disso, os pacientes que apresentaram maior tempo de doença tiveram maiores níveis de IS, sugerindo que a preocupação com a saúde bucal reduz com maior tempo de LESJ, possivelmente também relacionada a maior preocupação com a saúde sistêmica.

Por sua vez, pacientes com doenças crônicas na infância e adolescência têm um maior número de refeições durante o dia, com uma exposição ao açúcar mais freqüente. O longo tempo de uso de medicações em solução oral que contenham açúcar pode aumentar as taxas de cáries e placa bacteriana. Entre 10 a $80 \%$ dos medicamentos utilizados nos pacientes com LESJ apresentam açúcar nas suas formulações tais como: analgésicos (paracetamol), antiinflamatório não hormonal (naproxeno), protetores gástricos (ranitidina) e corticosteróides (prednisolona). A utilização destas drogas no período noturno tem também um efeito deletério na higiene bucal, pois à noite o fluxo salivar é reduzido, diminuindo assim a proteção da saliva contra as cáries e placa bacteriana (Foster et al., 2005; Welbury et al., 2003).

Estudos avaliando a saúde bucal dos pacientes adultos com LES são escassos. Mutlu et al. (1993) não evidenciaram diferença estatística entre IP e IS em 27 pacientes adultos com LES e controles saudáveis pareado por sexo e idade. No entanto, um outro estudo descritivo evidenciou periodontite em 15/16 pacientes adultos com LES (Rhodus et al., 1990). 
Em relação ao LESJ, há alguns relatos de casos sobre doença periodontal. Nagler et al. (1999) descreveram uma paciente de 18 anos de idade com LESJ em atividade e periodontite grave difusa, acometendo toda a sua dentição cuja biópsia da gengiva mostrou intenso infiltrado linfocitário. Da mesma forma, Vogel (1981) relatou uma paciente de 17 anos de idade com gengivite grave e sangramento gengival espontâneo associado ao LESJ e trombocitopenia amegacariocítica.

Nos pacientes com AIJ, há vários trabalhos que relatam piores índices de saúde bucal nestes pacientes em relação aos controles saudáveis. Welbury et al. (2003), encontraram maiores valores de IP e IS nos pacientes com AlJ em relação a controles. Em um estudo realizado na Unidade de Reumatologia Pediátrica do ICr e Divisão de Odontologia do HCFMUSP, Savioli et al. (2004) demonstraram também maiores valores de IP e IS nos pacientes com AIJ versus controles saudáveis. Os pacientes que apresentaram comprometimento articular (artrite e/ou limitação à movimentação e/ou seqüela articular) de três ou mais articulações dos membros superiores tiveram maiores índices, sugerindo uma inadequada higiene bucal.

Na síndrome de Sjögren, a literatura diverge sobre a freqüência de doença periodontal. Alguns trabalhos relatam um risco aumentado para doença periodontal nestes pacientes e outros referem não existir um maior risco para o desenvolvimento de periodontite (Najera et al., 1997, Jorkjend et al., 2003). No presente estudo nenhum paciente apresentou essa síndrome. 
Nos pacientes adultos com insuficiência renal crônica, Souza et al., 2005 e Klassen et al., 2002 encontraram valores elevados de IP. Assim como, nas crianças com diabetes mellitus tipo I, o IS foi também significativamente maior em relação aos controles saudáveis (Siudikiene et al., 2005).

Estes achados corroboram que pacientes com doenças crônicas negligenciam a saúde bucal em virtude da grande preocupação com a saúde sistêmica.

Prevenção e tratamento da maioria das doenças periodontais são relativamente simples e efetivos, promovendo uma melhor qualidade de vida (Oh et al., 2002).

A ATM é responsável por parte do desenvolvimento mandibular, pois o maior centro do crescimento da mandíbula localiza-se no côndilo mandibular. Pacientes com AlJ podem apresentar diminuição do crescimento mandibular, resultando em alterações faciais como: perfil convexo, micrognatia, retrognatia e mordida aberta anterior. Saviolli et al. (2004) mostraram que $34,2 \%$ dos pacientes com AIJ apresentam perfil facial convexo e este tipo de perfil esteve relacionado à doença avançada com reabsorção parcial dos côndilos mandibulares. O mesmo não foi evidenciado nos pacientes com LESJ do presente estudo, pois raramente ocorre inflamação crônica nas articulações nesta doença, incluindo a ATM, o que explicaria a maior freqüência do perfil reto e a oclusão molar I nos dois grupos estudados.

Disfunção temporomandibular (DTM) são anormalidades da ATM, que provocam dores recorrentes, habitualmente crônicas e não progressivas. A dor pode ser muscular, articular ou mista (Siqueira, 2003). A etiologia ainda 
não é totalmente compreendida, porém com fatores de risco envolvidos em sua gênese, tais como: sexo feminino, idade avançada, anormalidades da oclusão dentária, parafunção mandibular, fatores emocionais e doenças sistêmicas (Siqueira, 2003, Vanderas et al., 2002). Estes fatores são considerados suficientes, mas nem sempre necessários para o desenvolvimento da DTM. Fatores locais como odontalgias, periodontopatias, infecções de vias aéreas superiores muitas vezes intensificam a sintomatologia destas disfunções. Dentre os sinais e sintomas comuns relacionados a DTM, destacam-se: dor a função, ruídos articulares, limitação de abertura bucal e alteração dos movimentos mandibulares (Bonjardim et al., 2005, Bonjardim et al., 2003, Siqueira, 2003). A prevalência destes sinais e sintomas é baixa na infância e adolescência, aumenta nos adultos jovens e tende a declinar nos idosos. Em crianças e adolescentes, a prevalência de DTM é de 6 a $68 \%$ e esta variação é explicada principalmente pelos diferentes critérios diagnósticos utilizados. Num estudo realizado por List et al. (1999) foi observado que os locais mais prevalentes de dor na região cefálica relatados pelas crianças examinadas foram: cabeça (21\%), região temporal $(12 \%)$, dor à abertura bucal e ou à mastigação (4\%), dor em face, mandíbula ou ATM (3\%).

Em relação ao índice de mobilidade mandibular três pacientes $(6,3 \%)$ do grupo com LESJ e nenhum do grupo controle apresentaram disfunção grave. Esta diferença estatística ocorreu devido à redução dos movimentos mandibulares de lateralidades direita e esquerda. Neste estudo, quatro pacientes com LESJ (8,3\%) apresentaram disfunção clínica grave da ATM 
enquanto que nenhum paciente do grupo controle apresentou este grau de disfunção. Isto ocorreu devido a presença de desvio em fechamento da ATM acima de $2 \mathrm{~mm}$ nos pacientes com LESJ.

O principal músculo responsável pela lateralidade é o músculo pterigoideo lateral. Neste estudo, este músculo poderia estar comprometido por miosite ou vasculite pregressa, assim como pelos medicamentos utilizados, como corticosteróides que poderiam causar atrofia muscular localizada. A presença de desvio em fechamento de ATM pode ser secundária ao envolvimento muscular. Um outro aspecto interessante evidenciado neste estudo foi que os pacientes com LESJ em uso de um ou mais imunossupressores apresentaram disfunção da ATM em relação aos que não utilizaram estas drogas, podendo ser justificada pela maior gravidade da doença.

A radiografia panorâmica de mandíbula, apesar de ser um exame de pouca precisão, permite visualização do esqueleto facial, incluindo a ATM, com boa definição dos côndilos mandibulares. Como vantagens, a radiografia panorâmica apresenta baixo custo, baixa irradiação e fácil execução. Por sua vez, a tomografia computadorizada e particularmente a ressonância nuclear magnética mostram detalhes adicionais indispensáveis na avaliação da ATM e permitem a detecção de alterações musculares, sinoviais e cartilaginosas mais precoces nessa articulação.

Neste estudo, $54,2 \%$ dos pacientes realizaram radiografia panorâmica de mandíbula e destes apenas dois $(7,6 \%)$ apresentaram alterações importantes nos côndilos mandibulares. Estes dois pacientes que 
apresentaram radiografia compatível com Grau 2 ou 3 realizaram tomografia computadorizada da mandíbula que evidenciaram: redução do espaço articular bilateralmente, irregularidade e alterações erosivas dos platôs articulares com aplainamento articular sugestivo de necrose vascular da ATM. Apesar desses pacientes não relatarem dor orofacial, eles apresentaram uma leve DTM ao exame odontológico. Além disso, no momento da realização do exame, eles não tinham síndrome antifosfolípide e infecções (osteomielite e artrite séptica), indicando que os achados radiográficos foram compatíveis com necrose vascular da ATM conseqüente a corticoterapia crônica.

Sintomas articulares são extremamente comuns nos pacientes com LESJ e quase metade dos pacientes apresenta estes sintomas no início da doença. Geralmente, a artrite é aguda e não deformante, afetando principalmente pequenas articulações das mãos e pés (Lehman, 2001).

O envolvimento da ATM tem sido raramente descrito em pacientes adultos com LES e não há relatos de casos de disfunção da ATM nos pacientes com LESJ até o presente momento. Jonsson et al. (1983) estudaram o envolvimento da ATM em 37 pacientes adultos com LES comparados com grupo controle saudável, pareado por sexo e idade. Esses pacientes apresentaram queixas orofaciais em $14 \%$ dos casos caracterizadas por dor a palpação, dor a movimentação na ATM e desvio da ATM versus $3 \%$ dos controles. Dentre os pacientes com LES, 30\% apresentaram alguma anormalidade na radiografia panorâmica como achatamento do côndilo mandibular, osteófitos ou erosões articulares versus $9 \%$ dos controles. 
Erosões articulares foram encontradas em $11 \%$ dos pacientes com LES versus $1 \%$ dos controles. Há alguns relatos de casos com erosões na ATM em adultos com LES (Liebling et al., 1981, Tuggle, 1985) e outros relatos descrevendo existência de necrose avascular da ATM (Grinin et al., 1999). Entretanto, não há relato em crianças e adolescentes com LESJ.

Jonsson et al. (1984) estudaram 51 pacientes adultos com LES e evidenciaram lesões de mucosa oral características do LES em 13, tais como: lesões discóides em oito, eritemas em seis e úlceras orais em um. Por sua vez, as presenças destas lesões não foram correlacionadas com a atividade da doença. Neste estudo, apenas três pacientes $(6,3 \%)$ tiveram lesões eritematosas não ulceradas de palato duro. No presente estudo, os índices odontológicos e as lesões orais não estiveram relacionados com manifestações clínicas, atividade do LESJ e piores cursos da doença. Assim sendo, higiene oral prejudicada, a maior freqüência de gengivite e a disfunção da ATM não estiveram correlacionadas com uma maior atividade do LESJ. Com relação ao dano cumulativo e irreversível da doença também não houve correlação estatística entre este escore e os índices odontológicos avaliados.

Odontologistas devem entender sumariamente as múltiplas apresentações do LESJ, os eventos adversos do tratamento e as conseqüências na saúde bucal dos pacientes. Antes de iniciar um procedimento dentário, o odontologista deve considerar o grau de imunossupressão do paciente, assim como os riscos de sangramento, insuficiência renal e endocardite, além disso diagnosticar e tratar as 
múltiplas manifestações orofaciais do LESJ. Algumas medidas podem ser adotadas para minimizar o estresse durante o procedimento odontológico tais como: marcação de consultas no período da manhã, uso de medicação sedativa e uso de anestesia local profunda. Recomenda-se antibioticoterapia profilática nos pacientes em uso de imunossupressores; uso cauteloso de antiinflamatório não hormonal e respeitar os intervalos necessários das doses de medicamentos para pacientes com insuficiência renal crônica. Os procedimentos eletivos devem ser adiados durante as reativações do LESJ e nos casos que necessitam pulsoterapias com corticosteróide ou ciclofosfamida. A radiografia panorâmica de ATM deve ser realizada anualmente em todos os pacientes com LESJ para avaliar possíveis alterações ósseas desta articulação (De Rossi et al., 1998; Hughes et al., 1998).

Assim sendo, torna-se indispensável orientar e encorajar o paciente com LESJ a manter uma adequada saúde bucal, assim como consultas freqüentes ao odontologista. Os pais e responsáveis também deveriam ser treinados para auxiliar os pacientes na realização da higiene oral, com escovação adequada e uso de fio dental após todas as refeições. Orientações nutricionais, particularmente redução da ingestão de açúcar e consultas odontológicas periódicas ajudariam no manejo de doenças infecciosas como cárie e doença periodontal.

Estudos futuros avaliando o comprometimento muscular e articular, com ressonância nuclear magnética, destes pacientes são importantes para avaliar o sistema mastigatório. 
6. CONCLUSÕES 
1. Os pacientes com LESJ apresentaram uma precária higiene oral, maior freqüência de gengivite e disfunção da ATM em relação ao grupo controle.

2. Alterações orofaciais não foram associadas com manifestações clínicas, atividade da doença, dano cumulativo e alterações laboratoriais nos pacientes com LESJ.

3. Os índices de saúde bucal destes pacientes foram associados ao maior tempo da doença e à dose cumulativa de corticosteróides utilizada.

4. Os pacientes com LESJ em uso de um ou mais imunossupressores apresentaram disfunção da ATM em relação aos que não utilizaram estas drogas. 
7. ANEXOS 


\section{ANEXO A}

\section{CRITÉRIOS DO AMERICAN COLLEGE OF RHEUMATOLOGY PARA A CLASSIFICAÇÃO DE LÚPUS ERITEMATOSO SISTÊMICO (Hochberg, 1997).}

\section{Critérios de Classificação}

1. Eritema malar

2. Eritema discóide

3. Fotossensibilidade

4. Úlceras de mucosa (oral ou nasal)

5. Artrite não erosiva

6. Serosite (pleurite ou pericardite)

7. Doença renal:

A - proteinúria persistente ou superior a $0,5 \mathrm{~g} / \mathrm{dia}$

B - cilindrúria: cilindros hemáticos, hemoglobínicos, granulares, tubularesou mistos

8. Doença neurológica

A - psicose (excluindo-se drogas e distúrbios metabólicos)

B - convulsão (excluindo-se drogas e distúrbios metabólicos)

9. Doença hematológica

A - anemia hemolítica com reticulocitose em duas ou mais ocasiões

B - leucopenia (leucócitos menor que $4.000 / \mathrm{mm}^{3}$ ) em duas ou mais ocasiões

C - plaquetopenia (plaquetas menor que $100.000 / \mathrm{mm}^{3}$ ) em duas ou maisocasiões

D - linfopenia (linfócitos menor que $1.500 / \mathrm{mm}^{3}$ ) em duas ou mais ocasiões

10. Alterações imunológicas: anticorpo anti-DNA e/ou anticorpo anti-Sm e/ou anticorpo antifosfolípide (anticardiolipina e/ou anticoagulante lúpico) IgG e/ou IgM e/ou VDRL falso-positivo

11. Fator anti-núcleo (FAN) positivo

Para o diagnóstico é necessária a presença de 4 ou mais dos 11 critérios, simultaneamente ou evolutivamente, durante qualquer intervalo de tempo. 


\section{ANEXO B}

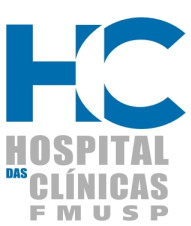

Instituto da Criança

Prof. Pedro de Alcantara Hospital das Clínicas - FMUSP

\section{TERMO DE CONSENTIMENTO LIVRE E ESCLARECIDO PARA O PACIENTE COM LÚPUS ERITEMATOSO SISTÊMICO JUVENIL}

I - DADOS DE IDENTIFICAÇÃO DO SUJEITO DA PESQUISA OU RESPONSÁVEL LEGAL

1. NOME DO PACIENTE :

DOCUMENTO DE IDENTIDADE N ${ }^{\circ}$ : SEXO : $M \square \quad F$ DATA NASCIMENTO .................. $\mathrm{N}^{\circ}$ APTO:

ENDEREÇO CIDADE

CEP: TELEFONE: DDD ( ..)

2. RESPONSÁVEL LEGAL

NATUREZA (grau de parentesco, tutor, curador etc.) DOCUMENTO DE IDENTIDADE DATA NASCIMENTO.: ..................... ENDEREÇO BAIRRO: CEP:. TELEFONE: DDD ( SEXO: $M$ $\mathrm{F}$ $\mathrm{N}^{\circ}$ APTO: CIDADE

II - DADOS SOBRE A PESQUISA CIENTÍFICA

1. TÍTULO DO PROTOCOLO DE PESQUISA Avaliação do comprometimento orofacial nos pacientes com lúpus eritematoso sistêmico juvenil

2. PESQUISADOR: Clovis Artur Almeida Silva CARGO/ FUNÇÃO: Médico Responsável pela Unidade de Reumatologia Pediátrica INSCRIÇÃO CONSELHO REGIONAL: CRM 64724 UNIDADE DO HC FMUSP: Unidade de Reumatologia Pediátrica do ICr- HC- FMUSP

3. AVALIAÇÃO DO RISCO DA PESQUISA:

$\begin{array}{lllll}\text { SEM RISCO } & \square & \text { RISCO MÍNIMO } & x & \text { RISCO MÉDIO } \\ \text { RISCO BAIXO } & \square & \text { RISCO MAIOR } & \square\end{array}$

(probabilidade de que o indivíduo sofra algum dano como conseqüência imediata ou tardia do estudo)

4. DURAÇÃO DA PESQUISA : março de 2004 a julho de 2005 
III -REGISTRO DAS EXPLICAÇÕES DO PESQUISADOR AO PACIENTE OU SEU REPRESENTANTE LEGAL SOBRE A PESQUISA, CONSIGNANDO:

1. Justificativa e os objetivos da pesquisa: Avaliar o comprometimento da boca, dentes, gengiva e mandibula nos pacientes com Lúpus Eritematoso Sistêmico Juvenil.

2. Procedimentos que serão utilizados e propósitos, incluindo a identificação dos procedimentos que são experimentais: Avaliação da boca, dentes, gengiva e mandibula dos pacientes com Lúpus Eritematoso Sistêmico Juvenil através de um exame feito pelo dentista.

3. Desconfortos e riscos esperados: Todos os pacientes serão submetidos a uma avaliação realizada pelo dentista e se tiverem cáries ou outras inflamações na boca, será feito tratamento adequado sempre sob efeito de anestesia.

4. Procedimentos alternativos que possam ser vantajosos para o indivíduo: Tratamento das cáries e outras alterações da boca que podem atrapalhar o Lúpus Eritematoso Sistêmico Juvenil.

\section{IV - ESCLARECIMENTOS DADOS PELO PESQUISADOR SOBRE GARANTIAS DO SUJEITO DA} PESQUISA:

1. Todo paciente que participar do estudo pode se informar, a qualquer momento, dos exames necessários, riscos e vantagens do estudo, e sempre pode tirar dúvidas com os responsáveis pela pesquisa.

2. O paciente pode deixar de participar da pesquisa a qualquer momento e isto não causará nenhum prejuízo ao tratamento realizado no Hospital das Clínicas.

3. O estudo é sigiloso e privativo. As informações tiradas do estudo são confidenciais, não podendo ser contadas para nenhuma outra pessoa além dos responsáveis pela pesquisa.

4. Caso aconteça algum dano à saúde do paciente, decorrentes da pesquisa, ele terá o tratamento adequado, completo e gratuito no Hospital das Clínicas.

\section{INFORMAÇÕES DE NOMES, ENDEREÇOS E TELEFONES DOS RESPONSÁVEIS PELO ACOMPANHAMENTO DA PESQUISA, PARA CONTATO EM CASO DE INTERCORRÊNCIAS CLÍNICAS E REAÇÕES ADVERSAS.}

Dra Elisabeth Gonzaga Canova Fernandes

Unidade de Reumatologia Pediátrica - Instituto da Criança- HC-FMUSP

Av. Dr. Enéas Carvalho de Aguiar, 647

CEP 05403-900 - São Paulo- SP

TELEFONES: (0xx11) 30698510/30698675

FAX: (0xx11) 30698503 
VI - CONSENTIMENTO PÓS-ESCLARECIDO

Declaro que, após convenientemente esclarecido pelo pesquisador e ter entendido o que me foi explicado, consinto em participar do presente Protocolo de Pesquisa

São Paulo, de de $2 \ldots \ldots . . . .$.

$\overline{\text { assinatura do sujeito da pesquisa ou responsável legal }}$

assinatura do pesquisador

(Dr ${ }^{a}$ Elisabeth G. C. Fernandes) 
ANEXO C

\section{CLASSE SÓCIO-ECONÔMICA ABA-ABIPEMI}

Almeida et al. (1991)

A. Quem é o chefe da família na sua casa? ( ) o próprio entrevistado ( ) outros

B. Qual foi o último ano da escola que o chefe da família cursou?

\begin{tabular}{|l|c|}
\hline Grau de instrução máximo & Pontos \\
\hline Não estudou ou primário incompleto & 0 \\
\hline Primário completo ou ginásio incompleto & 05 \\
\hline Ginásio completo ou colegial incompleto & 10 \\
\hline Colegial incompleto ou universitário incompleto & 15 \\
\hline Universitário completo & 21 \\
\hline
\end{tabular}

C. Na sua casa tem?

Aparelho de vídeo cassete

Máquina de lavar roupas

( ) não

( ) $\operatorname{sim}(10$ pontos)

Geladeira

( ) não

( ) $\operatorname{sim}$ (08 pontos)

Aspirador de pó

( ) não

( ) $\operatorname{sim}$ (07 pontos)

( ) não

( ) $\operatorname{sim}$ (06 pontos)

D. Quantos (cada item abaixo) existem em sua casa?

\begin{tabular}{|c|c|c|c|c|c|c|c|}
\hline Item & $\begin{array}{c}\text { Nenhum } \\
\text { item } \\
\text { (pontos) }\end{array}$ & $\begin{array}{c}1 \\
\text { (pontos) }\end{array}$ & $\begin{array}{c}2 \\
\text { (pontos) }\end{array}$ & $\begin{array}{c}3 \\
\text { (pontos) }\end{array}$ & $\begin{array}{c}4 \\
\text { (pontos) }\end{array}$ & $\begin{array}{c}5 \\
\text { (pontos) }\end{array}$ & $\begin{array}{c}6 \text { ou }+ \\
\text { itens } \\
\text { (pontos) }\end{array}$ \\
\hline Carros & 0 & 4 & 9 & 13 & 18 & 22 & 26 \\
\hline TV em cores & 0 & 4 & 7 & 11 & 14 & 18 & 22 \\
\hline Banheiros & 0 & 2 & 5 & 7 & 10 & 12 & 15 \\
\hline $\begin{array}{c}\text { Empregada } \\
\text { mensalista }\end{array}$ & 0 & 5 & 11 & 16 & 21 & 26 & 32 \\
\hline Rádio & 0 & 2 & 3 & 5 & 6 & 8 & 9 \\
\hline
\end{tabular}

\begin{tabular}{|c|c|}
\hline CLASSES SÓCIO - ECONÔMICAS ABA-ABIPEMI & TOTAL DE PONTOS \\
\hline A & 89 OU MAIS \\
\hline B & 59 A 88 \\
\hline C & 35 A 58 \\
\hline D & 20 A 34 \\
\hline E & 0 A 19 \\
\hline
\end{tabular}




\section{ANEXO D}

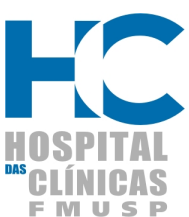

Instituto da Criança

Prof. Pedro de Alcantara Hospital das Clínicas - FMUSP

\section{TERMO DE CONSENTIMENTO LIVRE E ESCLARECIDO PARA O PACIENTE DO GRUPO CONTROLE}

I - DADOS DE IDENTIFICAÇÃO DO SUJEITO DA PESQUISA OU RESPONSÁVEL LEGAL

1. NOME DO PACIENTE :

DOCUMENTO DE IDENTIDADE No : SEXO : $M \square \quad F$ DATA NASCIMENTO: ................... $\mathrm{N}^{\circ}$ APTO:

BAIRRO: CIDADE

CEP: TELEFONE: DDD ( ..)

2. RESPONSÁVEL LEGAL

NATUREZA (grau de parentesco, tutor, curador etc.) DOCUMENTO DE IDENTIDADE DATA NASCIMENTO : ......./.............. ENDEREÇO BAIRRO: APTO: CEP: TELEFONE: DDD (

CIDADE $\mathrm{N}^{\circ}$

SEXO: $M$

II - DADOS SOBRE A PESQUISA CIENTÍFICA

1. TÍTULO DO PROTOCOLO DE PESQUISA Avaliação do comprometimento orofacial nos pacientes do grupo controle

2. PESQUISADOR: Clovis Artur Almeida Silva

CARGO/ FUNÇÃO: Médico Responsável pela Unidade de Reumatologia Pediátrica INSCRIÇÃO CONSELHO REGIONAL: CRM 64724

UNIDADE DO HC FMUSP: Unidade de Reumatologia Pediátrica do ICr- HC- FMUSP

3. AVALIAÇÃO DO RISCO DA PESQUISA:

$\begin{array}{lllll}\text { SEM RISCO } & \square & \text { RISCO MÍNIMO } & x & \text { RISCO MÉDIO } \\ \text { RISCO BAIXO } & \square & \text { RISCO MAIOR } & \square\end{array}$

(probabilidade de que o indivíduo sofra algum dano como consequência imediata ou tardia do estudo)

4. DURAÇÃO DA PESQUISA : março de 2004 a julho de 2005 
III -REGISTRO DAS EXPLICAÇÕES DO PESQUISADOR AO PACIENTE OU SEU REPRESENTANTE LEGAL SOBRE A PESQUISA, CONSIGNANDO:

1. Justificativa e os objetivos da pesquisa: Avaliar o comprometimento da boca, dentes, gengiva e mandíbula nos pacientes do grupo controle.

2. Procedimentos que serão utilizados e propósitos, incluindo a identificação dos procedimentos que são experimentais: Avaliação da boca, dentes, gengiva e mandíbula dos pacientes do grupo controle através de um exame feito pelo dentista.

3. Desconfortos e riscos esperados: Todos os pacientes serão submetidos a uma avaliação realizada pelo dentista e se tiverem cáries ou outras inflamações na boca, será feito tratamento adequado sempre sob efeito de anestesia.

4. Procedimentos alternativos que possam ser vantajosos para o indivíduo: Tratamento das cáries e outras alterações da boca que podem atrapalhar a saúde bucal em geral.

IV - ESCLARECIMENTOS DADOS PELO PESQUISADOR SOBRE GARANTIAS DO SUJEITO DA PESQUISA:

1. Todo paciente que participar do estudo pode se informar, a qualquer momento, dos exames necessários, riscos e vantagens do estudo, e sempre pode tirar dúvidas com os responsáveis pela pesquisa.

2. O paciente pode deixar de participar da pesquisa a qualquer momento e isto não causará nenhum prejuízo ao tratamento realizado no Hospital das Clínicas.

3. O estudo é sigiloso e privativo. As informações tiradas do estudo são confidenciais, não podendo ser contadas para nenhuma outra pessoa além dos responsáveis pela pesquisa.

4. Caso aconteça algum dano à saúde do paciente, decorrentes da pesquisa, ele terá o tratamento adequado, completo e gratuito no Hospital das Clínicas.

\section{INFORMAÇÕES DE NOMES, ENDEREÇOS E TELEFONES DOS RESPONSÁVEIS PELO ACOMPANHAMENTO DA PESQUISA, PARA CONTATO EM CASO DE INTERCORRÊNCIAS CLÍNICAS E REAÇÕES ADVERSAS.}

Dr ${ }^{\mathrm{a}}$ Elisabeth Gonzaga Canova Fernandes

Unidade de Reumatologia Pediátrica - Instituto da Criança- HC-FMUSP

Av. Dr. Enéas Carvalho de Aguiar, 647

CEP 05403-900 - São Paulo- SP

Telefones: (0XX11) 30698510/ 30698675

FAX: (0xx11) 30698503 
VI - CONSENTIMENTO PÓS-ESCLARECIDO

Declaro que, após convenientemente esclarecido pelo pesquisador e ter entendido o que me foi explicado, consinto em participar do presente Protocolo de Pesquisa

São Paulo, de de $2 \ldots \ldots . . . .$.

$\overline{\text { assinatura do sujeito da pesquisa ou responsável legal }}$

assinatura do pesquisador

(Dr ${ }^{a}$ Elisabeth G. C. Fernandes) 


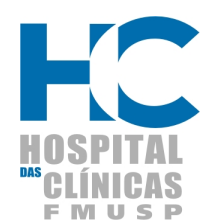

\section{PROTOCOLO DE AVALIAÇÃO DO COMPROMETIMENTO OROFACIAL NOS PACIENTES COM LESJ E GRUPO CONTROLE}

\section{IDENTIFICAÇÃO}

Nome: Registro:

Pai: Mãe:

Data de nascimento: Idade atual:

Data da $1^{a}$ consulta:

Raça: Sexo: dade de início do LESJ: Tempo de duração do LESJ: Data avaliação:

Naturalidade: Procedência atual:

Endereço:

CEP: Bairro Cidade: Estado

Escolaridade: Profissão:

Classe sócio-econômica:

\section{MANIFESTAÇÕES CLÍNICAS DO LES}

Sintomas constitucionais

Febre

Perda de peso

Sistema retículo-endotelial

Adenomegalia

Hepatomegalia

Esplenomegalia

Cutâneo-mucoso

Eritema malar

Vasculite cutânea

Fotossensibilidade

Livedo reticular

úlceras orais

Músculo-esquelético

Artrite

Miosite

Osteonecrose

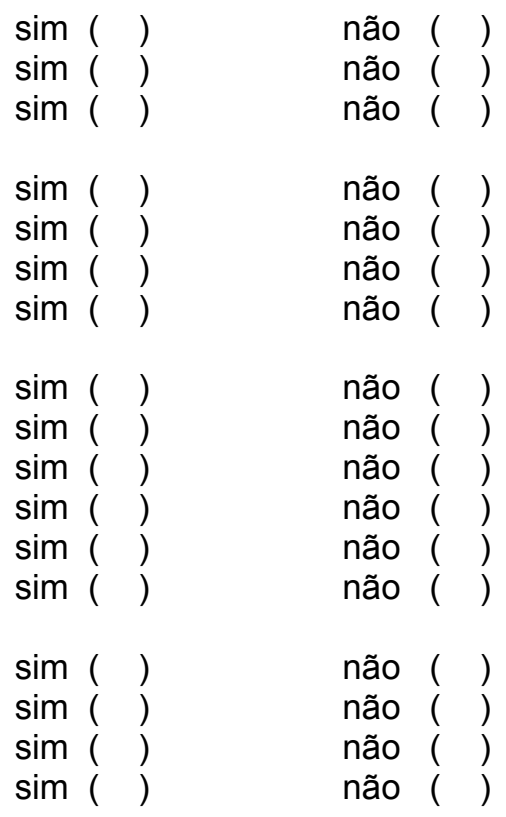


Cardíaco

Pericardite

Miocardite

Valvulite

Pulmonar

Pleurite

Pneumonite intersticial

Sistema nervoso central

Cefaléia importante

Convulsão

Distúrbio do comportamento

Acidente vascular cerebral

Psicose

Coréia

Amaurose fugaz

Coma

Mielite transversa

Comprometimento renal

Hipertensão arterial

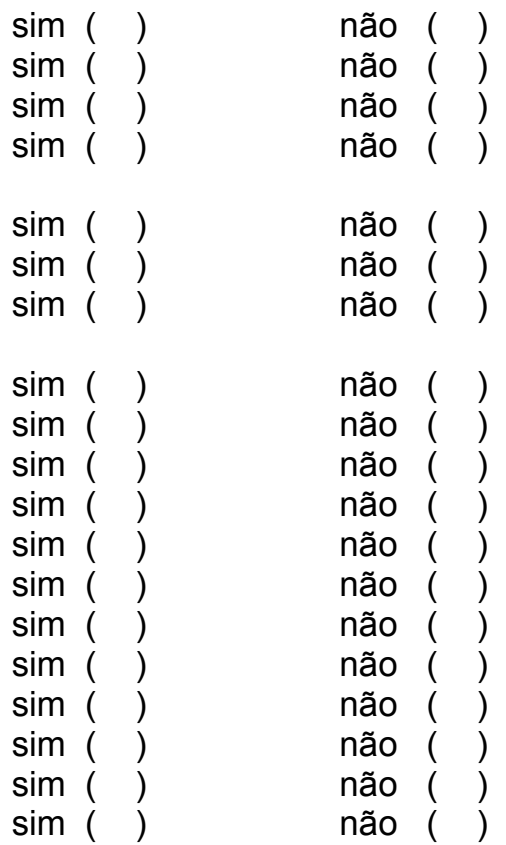

\section{MANIFESTAÇÕES LABORATORIAIS DO LES}

Renal

Hematúria

Leucocitúria

Cilindrúria

Proteinúria

Insuficiência renal

Biópsia Classe histológica OMS

\section{Hematológico}

Anemia hemolítica

Leucopenia

Linfopenia

Plaquetopenia

Alterações de coagulação

$\downarrow \mathrm{C} 3, \downarrow \mathrm{C} 4, \downarrow \mathrm{CH} 50$

Autoanticorpos
FAN
anti-DNA
anti-Sm
anti-RNP
anti-RO
anti-La
anti P
anti Clp IgM
anti Clp IgG
anticoagulante lúpico

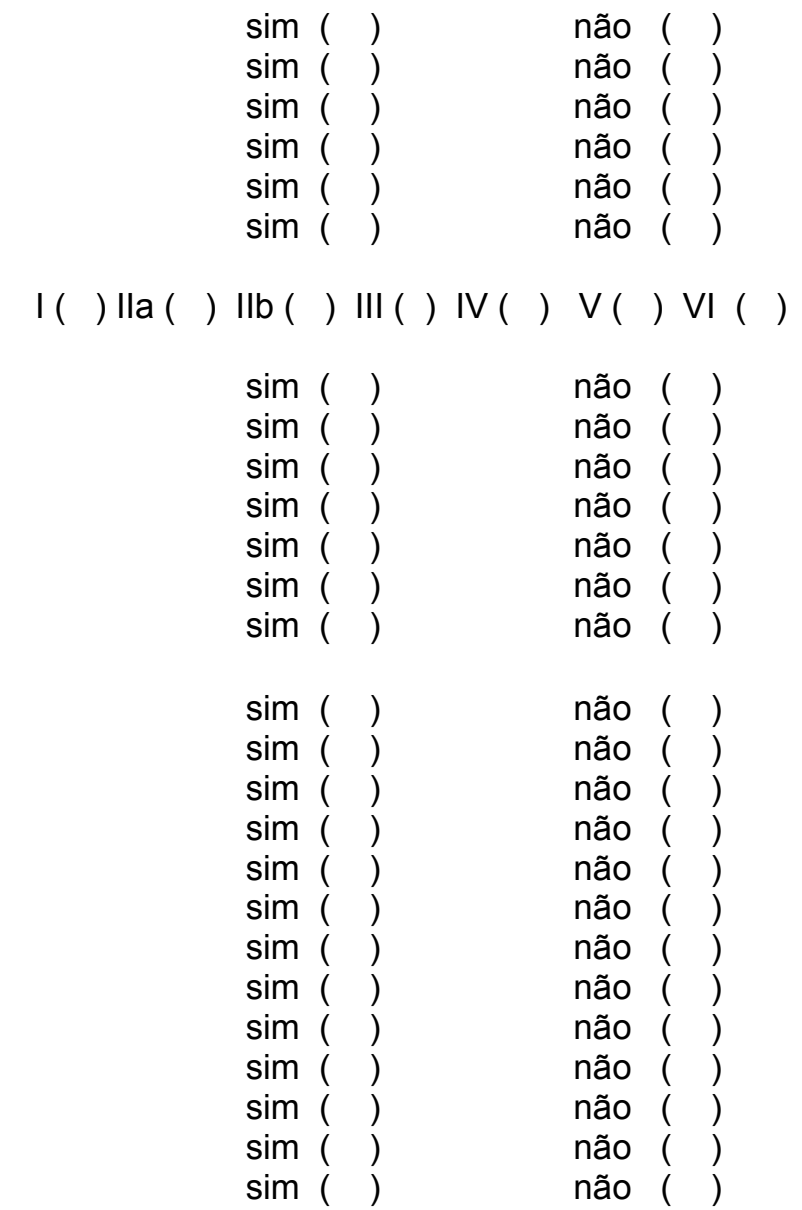




\section{ATIVIDADE, CURSO E DANO ACUMULATIVO DO LESJ}

\section{SLEDAI}

SLICC/ACR-DI

CURSO do LESJ: remissivo-recidivante ( )

ativo-crônico ( )

remissivo

\section{TRATAMENTO UTILIZADO}

- corticosteróides (prednisona/metilprednisolona/hidrocortisona)

dose total: tempo de uso:

efeitos colaterais:

- pulsoterapia com ciclofosfamida

$n^{\circ}$ pulsos (dose/indução):

$n^{\circ}$ pulsos (dose/manutenção):

dose total:

tempo de uso:

indicação:

efeitos colaterais:

- metotrexato

dose semanal: dose total:

via de administração $(\mathrm{VO}, \mathrm{IM}, \mathrm{SC})$ :____ _ tempo de uso: efeitos colaterais:

- azatioprina

dose diária: dose total:

tempo de uso:

efeitos colaterais:

- ciclosporina

dose diária: dose total:

tempo de uso:

efeitoscolaterais:

- $\quad$ micofenolato mofetil

dose diária: dose total:

tempo de uso:

efeitoscolaterais:

- cloroquina/ hidroxicloroquina

dose diária: dose total:

tempo de uso:

efeitoscolaterais:

- outras drogas:

dose diária: dose total:

tempo de uso:

efeitoscolaterais: 


\section{AVALIAÇÃO DO COMPROMETIMENTO OROFACIAL}

\section{* Condição bucal:}

1. Dentes:

- Índice cpo-d (Klein e Palmer) : C + P $(E i+E)+O=0$ à 28

- Índice ceo-d (Gruebbel) : C + E + O = 0 à 20.

\begin{tabular}{llllllll|llllllll}
18 & 17 & 16 & 15 & 14 & 13 & 12 & 11 & 21 & 22 & 23 & 24 & 25 & 26 & 27 & 28 \\
\hline 48 & 47 & 46 & 45 & 44 & 43 & 42 & 41 & 31 & 32 & 33 & 34 & 35 & 36 & 37 & 38
\end{tabular}

- Dentes ausentes:

2. Gengiva:

- Índice de Ramfjord (específico para placa): $\underline{\mathrm{n} .{ }^{\circ} \text { de faces coradas } \times 100}=$ $\%$ n. ${ }^{\circ}$ de dentes $\times 4$

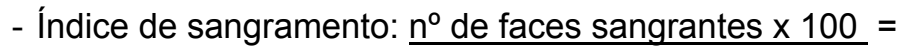
$\%$ $\mathrm{n}^{\circ}$ de dentes $\mathrm{x} 4$
3. Tipo de oclusão: ( ) Cl I Angle
( ) Cl II Angle
( ) Cl III Angle

4. Perfil: ( ) côncavo ( ) convexo ( ) reto

\section{* Condição articular:}

- Avaliação clínica

5. Queixa principal / duração:

6. Localização da dor:

7. Fator inicial:

8. Tratamentos realizados para a dor:

9. Tipo de dor: ( ) pontada ( ) peso ( ) queimação ( ) choque ( ) latejante

10. É espontânea?

$$
\text { ( ) cansaço ( ) outros }
$$

11. Frequência da dor: ( ) diária ( ) dias alternados ( ) quinzenal ( ) mensal ( ) esporádica

12. Período de piora: ( ) manhã ( ) tarde ( ) noite ( ) indiferente

13. Intensidade da dor: ( ) fraca ( ) moderada ( ) forte Nota:

14. Consegue localizar a dor:

15. Fatores de melhora: ( ) frio ( ) calor ( ) medicamento ( ) outros

16. Fatores de piora: ( ) frio ( ) calor ( ) doce ( ) tensão emocional

17. Sente o rosto cansado?
( ) mastigação
( ) fala ( ) bocejo ( ) outros

18. Mastigação é: ( ) D ( )E ( ) bilateral ( ) a frente 
24. Rx panorâmico:

- Forma dos côndilos e dos ramos mandibulares:

( ) Grau 0: sem anormalidades radiográficas

Superfície óssea articular do condilo com contornos convexos e bem definido

( ) Grau 1: Anormalidade leve

Defeitos na borda condilar, erosões menores

( ) Grau 2: Anormalidade moderada

Aplainamento do côndilo.

( ) Grau 3: Anormalidade grave

Destruição total do côndilo

- Avaliação dos dentes, periodonto e osso alveolar. 


\section{ANEXO F}

\section{ÍNDICE DE ATIVIDADE DA DOENÇA DO LÚPUS ERITEMATOSO} SISTÊMICO (SLEDAI) - BOMBARDIER ET AL. (1992)

\begin{tabular}{|c|c|c|}
\hline MANIFESTAÇÃO & DEFINIÇÃO & PESO \\
\hline CONVULSÃO & Excluir causas metabólicas, infecciosas ou drogas. & 8 \\
\hline PSICOSE & $\begin{array}{l}\text { Alteração da percepção da realidade, incluindo-se } \\
\text { alucinações, incoerências, pensamento desorganizado, } \\
\text { catatonia. Excluir drogas e uremia. }\end{array}$ & 8 \\
\hline $\begin{array}{l}\text { SÍNDROME } \\
\text { ORGÂNICO-CEREBRAL }\end{array}$ & $\begin{array}{l}\text { Alteração mental com déficit de orientação, memória, } \\
\text { julgamento e atenção, com dois de: fala incoerente, } \\
\text { insônia, sonolência, hipo/hiperatividade motora. Excluir } \\
\text { causas metabólicas, infecciosas ou drogas. }\end{array}$ & 8 \\
\hline ALTERAÇÕES VISUAIS & $\begin{array}{l}\text { Corpos cetóides ou hemorragias retinianas, exsudatos } \\
\text { ou hemarrogias de coróide, neurite óptica. Excluir } \\
\text { causas infecciosas, drogas ou hipertensão. }\end{array}$ & 8 \\
\hline $\begin{array}{l}\text { ALTERAÇÕES DE } \\
\text { NERVOS CRANIANOS }\end{array}$ & Neuropatia motora ou sensorial. & 8 \\
\hline CEFALÉIA & $\begin{array}{l}\text { Persistente, intensa, tipo enxaqueca, não responsiva aos } \\
\text { analgésicos narcóticos. }\end{array}$ & 8 \\
\hline $\begin{array}{l}\text { ACIDENTE VASCULAR } \\
\text { CEREBRAL }\end{array}$ & Excluir aterosclerose. & 8 \\
\hline VASCULITES & $\begin{array}{l}\text { Úlceras, gangrena, nódulos dolorosos, infarto sub ou } \\
\text { periungueal, biópsia ou angiografia compatível. }\end{array}$ & 8 \\
\hline ARTRITES & Duas ou mais articulações. & 4 \\
\hline MIOSITES & $\begin{array}{l}\text { Fraqueza ou dor muscular proximal com: elevação de } \\
\text { enzimas musculares, eletromiografia ou biópsia } \\
\text { compatíveis. }\end{array}$ & 4 \\
\hline CILINDROS URINÁRIOS & Granulosos ou hemáticos. & 4 \\
\hline HEMATÚRIA & $\begin{array}{l}\text { Maior que } 5 \text { hemácias por campo. Excluir cálculos ou } \\
\text { infecções. }\end{array}$ & 4 \\
\hline PROTEINÚRIA & $\begin{array}{l}\text { Maior que } 0,5 \mathrm{~g} / \mathrm{dia} \text { de início recente ou aumento maior } \\
\text { que } 0,5 \mathrm{~g} / \mathrm{dia} \text { em relação aos valores anteriores. }\end{array}$ & 4 \\
\hline LEUCOCITÚRIA & Maior que 5 leucócitos por campo. Excluir infecções. & 4 \\
\hline ERITEMA MALAR & & 2 \\
\hline ALOPÉCIA & $\begin{array}{l}\text { Perda anormal de cabelos, de forma localizada ou } \\
\text { difusa. }\end{array}$ & 2 \\
\hline ÚLCERAS DE MUCOSAS & Úlceras orais ou nasais. & 2 \\
\hline PLEURITE & $\begin{array}{l}\text { Dor pleurítica, com atrito ou derrame pleural, ou } \\
\text { espessamento pleural. }\end{array}$ & 2 \\
\hline PERICARDITE & $\begin{array}{l}\text { Dor pericárdica com atrito, derrame ou } \\
\text { eletrocardiograma ou ecocardiograma compatíveis. }\end{array}$ & 2 \\
\hline $\begin{array}{l}\text { DIMINUIÇÃO DE } \\
\text { COMPLEMENTO }\end{array}$ & Diminuição de C3, C4 ou CH50. & 2 \\
\hline ANTI-DNA & Presença. & 2 \\
\hline FEBRE & Temperatura maior que $38^{\circ} \mathrm{C}$. Excluir infecções. & 1 \\
\hline PLAQUETOPENIA & Menor que 100.000 plaquetas por $\mathrm{mm}^{3}$ & 1 \\
\hline LEUCOPENIA & Menor que 3.000 leucócitos por $\mathrm{mm}^{3}$. Excluir drogas. & 1 \\
\hline
\end{tabular}

Obs: válido para manifestações de início recente (até dez dias anteriores à avaliação) 


\section{ANEXO G}

\section{Systemic Lupus International Collaborating Clinics/ACR-Damage Index (SLICC/ACR-DI) (Gladman et al., 1996)}

Data:

Tempo de seguimento

Ocular (qualquer olho, por avaliação clínica)

1 ( ) Catarata em qualquer época

1 ( ) Alteração retiniana ou atrofia óptica

\section{Neuropsiquiátrico}

1( ) Prejuízo cognitivo (p. ex. deficiência de memória, dificuldade com cálculo, dificuldade de concentração, dificuldade com linguagem escrita ou falada, prejuízo no nível de execução) ou Psicose

1 ( ) Convulsões requerendo tratamento por 6 meses

1 ( ) 2( ) AVC em qualquer época (pontuar 2 se >1)

1 ( ) Neuropatia craniana ou periférica (excluir óptica)

1 ( ) Mielite transversa

\section{Renal}

1 ( ) Taxa de filtração glomerular medida ou estimada $<50 \%$

1 ( ) Proteinúria $3,5 \mathrm{~g} / 24 \mathrm{~h}$

ou

3( ) Insuficiência renal terminal (a despeito de diálise ou transplante)

\section{Pulmonar}

1( ) Hipertensão pulmonar (aumento de VD ou hiperfonese de B2)

1 ( ) Fibrose pulmonar (ex. físico e radiográfico)

1 ( ) Pulmão retraído (radiográfico)

1 ( ) Fibrose pleural (radiográfico)

1 ( ) Infarto pulmonar (radiográfico)

\section{Cardiovascular}

$\begin{array}{ll}1(\text { ) } & \text { Angina ou ponte coronariana } \\ 1(\text { ) } 2(\text { ) } & \text { IAM em qualquer época (pontuar } 2 \text { se }>1 \text { ) } \\ 1(\text { ) } & \text { Miocardiopatia (disfunção ventricular) } \\ 1(\text { ) } & \text { Doença valvular (sopro diastólico ou sistólico }>3+/ 6+\text { ) } \\ 1(\text { ) } & \text { Pericardite por } 6 \text { meses ou pericardectomia }\end{array}$




\title{
Vascular periférico
}

\author{
1 ( ) Claudicação por 6 meses \\ 1 ( ) Perda tecidual menor (polpa digital) \\ 1 ( ) 2 ( ) Perda tecidual significativa em qualquer época (p. ex. dedo ou membro) \\ (pontuar 2 se $>1$ local) \\ 1( ) Trombose venosa com edema, ulceração ou estase venosa
}

\section{Gastrintestinal}

1 ( ) 2( ) Infarto ou ressecção de intestino (abaixo do duodeno), baço, fígado ou vesícula, em qualquer época e por qualquer causa (pontuar 2 se $>1$ local)

1 ( ) Insuficiência mesentérica

1 ( ) Peritonite crônica

1( ) Estenose ou cirurgia em TGI superior em qualquer época

\section{Músculo-esquelético}
1 ( ) Atrofia muscular ou fraqueza
1 ( ) Artrite erosiva ou deformante (inclui formas redutíveis e exclui necrose avascular)
1 ( ) Osteoporose com fratura ou colapso vertebral (exclui necrose avascular)
1 ( ) 2 ( ) Necrose avascular (pontuar 2 se >1)
$1($ ) Osteomielite

\begin{tabular}{ll}
\hline Pele & \\
$1($ ) & Alopecia crônica cicatricial \\
$1($ Cicatriz cutânea ou panicular extensa que não em polpa ou couro & cabeludo \\
$1($ ) & Úlcera cutânea (excluindo trombose) por $>6$ meses
\end{tabular}

\section{Outros}

$\begin{array}{ll}1(\text { ) } & \text { Falência gonadal prematura } \\ 1(\text { ) } & \text { Diabetes (a despeito de tratamento) } \\ 1(\text { ) } 2(\text { ) } & \text { Malignidade (exclui displasia) (pontuar } 2 \text { se }>1 \text { local) }\end{array}$

Total:

Dano (mudança irreversível, não relacionada com inflamação ativa) ocorrendo desde o início do Lúpus Eritematoso Sistêmico Juvenil, certificada por avaliação clínica e presente por pelo menos seis meses, a menos que ressalvado de outra forma. Episódios repetidos devem ocorrer com intervalos mínimo de seis meses para pontuarem. A mesma lesão não pode ser pontuada duas vezes. 


\section{REFERÊNCIAS}


Ainamo J, Bay I. Problems and proposals for recording gingivitis and plaque. International Dental Journal. 1975;25:229-35.

Albandar JM. Epidemiology and risk factors of periodontal diseases. Dent Clin North Am. 2005;49(3):517-32.

Almeida, PM, Wickerhauser, H. Critério ABA (Associação Brasileira de Anunciantes) e ABIPEME (Associação Brasileira dos Institutos de Pesquisa de Mercado). 1991; p.1-29.

Appenzeller S, Marini R, Costallat LT. Damage did not independently influence mortality in childhood systemic lupus erythematosus. Rheumatol Int. 2005;25:619-24.

Armitage GC. Development of a classification system for periodontal diseases and conditions. Ann Periodontal. 1999;4(1):1-6.

Barr SG, Zonana-Nacach A, Magder LS, Petri M. Patterns of disease activity in systemic lupus erythematosus. Arthritis Rheum. 1999;42:2682-8.

Bimstein E. Periodontal health and disease in children and adolescents. Pediatr Clin North Am. 1991;38:1183-1207.

Bombardier C, Gladman D, Urowitz MB, Karon D, Chang CH. Committee on prognosis studies in SLE. Derivation of SLEDAI. A disease activity index for lupus patients. Arthritis Rheum. 1992;35:630-40. 
Bonjardim LR, Gavião MBD, Pereira LJ, Castelo PM, Garcia RCMR. Signs and symptoms of temporomandibular disorders in adolescents. Bras Oral Res. 2005;19(2):93-8.

Bonjardim LR, Gavião MBD, Carmagnani FG, Pereira LJ, Castelo PM. Signs and symptoms of temporomandibular joint dysfunction in children with primary dentition. J Clin Pediatr Dent. 2003;28(1):53-8.

Brandão L, Sachetti S, Hilário MOE, Goldenberg J. Fatores prognósticos no lúpus eritematoso sistêmico da criança. Rev Bras Reumatol. 1994;34:321-8.

Burge SM, Frith PA, Juniper RP, Wojnarowska F. Mucosal involvement in systemic and chronic cutaneous lupus erythematosus. $\mathrm{Br} \mathrm{J}$ Dermatol. 1989;121:727-41.

Cameron JS. Lupus and lupus nephritis in children. Adv Neprhol. 1993;22:59-119.

Campos LM, Kiss MH, D'amico EA, Silva CA. Antiphospholipid antibodies and antiphospholipid syndrome in 57 children and adolescents with systemic lupus erythematosus. Lupus. 2003;12:820-6.

Canova EG, Rosa DC, Vallada MG, Silva CA. Invasive aspergillosis in juvenile systemic lupus erythematosus. A Clinicopathologic Case. Clin Exp Rheumatol. 2002;20:736.

Cardoso L, Rosing C, Kramer P, Costa CC, Costa LC. Polarização da cárie em município sem água fluoretada. Cad Saúde pública. 2003;19:237-43.

Carrel R, Anderson R, Jackson T, Slawek S. Systemic lupus erythematosus: a teenage patient. J Clin Pediatric Dent. 1990;15:55-9. 
Cassidy JT, Petty RE. Systemic lupus erythematosus. In: Cassidy JT, Petty RE. Textbook of Pediatric Rheumatology. 4ed. Philadelphia, Pennsylvania, WB Saunders Company. 2001;396-449.

Corby PM, Lyon-Weiler J, Bretz WA, Hart TC, Aas JA, Boumenna T, et al. Microbial risk indicators of early childhood caries. J Clin Microbiol. 2005;43(11):5753-9.

De Rossi SS, Glick M. Lupus erythematosus: considerations for dentistry. J Am Dent Assoc. 1998;129:330- 9.

Dibart S. Children, adolescents and periodontal diseases. J Dent. 1997;25:79-89.

English JD, Buschang PH, Throckmorton GS. Does malocclusion affect masticatory performance? Angle Orthod. 2002;72(1):21-7.

Facó MM, Nukumizu LA, Moraes AJP, Barros PCB, Troster EJ, Silva CAA. Avaliação dos óbitos e necrópsias em pacientes internados em um Serviço de Reumatologia Pediátrica por um período de 10 anos. Rev Brasil Reumatol. 2005;45:55-63.

Foster H, Fitzgerald J. Dental disease in children with chronic illness. Arch Dis Child. 2005;90:703-8.

Gladman D, Ginzler E, Goldsmith C et al. The development and initial validation of the Systemic Lupus International Collaborating Clinics/ American College of Rheumatology Damage Index for systemic lupus erythematosus. Arthritis Rheum. 1996;39:363-9. 
Grinin VM, Maksimovskii IM, Nasonova VA. Aseptic necrosis of the temporomandibular joint in systemic lupus eryhtematosus. Stomatologiia. 1999;78(6):23-7.

Hiláro MOE, Len CA, Sato El et al. Lúpus eritematoso sistêmico juvenil: resultados do estudo multicêntrico nacional. Rev Bras Reumatol. 2002;42:85-9.

Helkimo $\mathrm{H}$. Studies on function and dysfunction of the masticatory system. II. Index for anamnestic dysfunction and occlusal state. Swed Dent J. 1974;67:101-19.

Hochberg MC. Updating the American College of Rheumatology revised criteria for the classification of systemic lupus erythematosus. Arthritis Rheum. 1997;40:1725.

Hollister MC, Weintraub JA. The association of oral status with systemic health, quality of life, and economic productivity. J Dent Educ. 1993;57(12):901-12.

Hughes C T, Downey MC, Winkley G P. Systemic lupus erythematosus: a review for a dental professionals. J Dent Hyg. 1998;72(2):35-41.

Jonsson R, Heyden G, Westberg NG, Nyberg G. Oral mucosal lesions in systemic lupus erythematosus - a clinical, histopathological and immunopathological study. J Rheumatol. 1984;11:38-42.

Jonsson R, Lindvall AM, Nyberg G. Temporomandibular joint involvement in systemic lupus erythematosus. Arthritis Rheum. 1983;26(12):1506-10. 
Jorkjend L, Johansson A, Johansson AK, Bergenholtz A. Periodontitis, caries and salivary factors in Sjögren's syndrome patients compared to sex and age-matched.controls. Journal of oral rehabilitation. 2003;30:369-78.

Kjjellberg $\mathrm{H}$, Ekestubbe A, Killiardis S, Thilander B. Condylar height on panoramic radiographs. A methodologic study with a clinical application. Acta Odontol Scand. 1994;52:43-50.

Klassen JT, Krasko BM. The dental health status of dialysis patients. J Can Dental Assoc. 2002;68:34-8.

Lehman TJA. A practical guide to systemic lupus erythematosus. Ped Clin North Am. 1995;42:1223-7.

Lehman TJA, Mc Curdy DK, Bernstein BH, King KK, Hanson V. Systemic lupus erythematosus in the first decade of life. Pediatrics. 1989;83:235-9.

Lehman TJA. Systemic lupus erythematosus in childhood and adolescence. In: Wallace DJ, Hahn BH. Dubois' Lupus Erythematosus. 6th ed. Lippincott, Williams \& Williams. 2001;863-84.

Liebling MR, Gold RH. Erosions of the temporomandibular joint in systemic lupus erythematosus. Arthritis Rheum. 1981;24(7):948-50.

Liphaus BL, Goldenberg AC, Kiss MH, Silva CA. Analysis of human leukocyte antigens of class II-DR in Brazilian children and adolescents with Systemic Lupus Erythematosus. Rev Hosp Clin Fac Med S Paulo. 2002;57(6):277-82.

List T, Wahlund K, Wenneberg B, Dworkin SF. TMD in children and adolescents: prevalence of pain, gender differences and perceived treatment need. J Orof Pain. 1999;13:9-20. 
Mc Curdy DK, Lehman TJA, Bernstein B et al. Lupus nephritis: prognostic factors in children. Pediatrics. 1992;89:240-6.

Mutlu S, Richards A, Maddison P, Scully C. Gingival and periodontal health in systemic lupus erythematosus. Community Dent Oral Epidemiol. 1993;21:158-61.

Nagler RM, Lorber M, Ben-Arieh Y, Laufer D, Pollack S. Generalized periodontal involvement in a young patient with systemic lupus erythematosus. Lupus. 1999;8:770-2.

Najera MP, Al-Hashimi I, Plemons JM, Rivera-Hidalgo F, Rees TD, Haghighat N, Wright JM. Prevalence of periodontal disease in patients with Sjögren's syndrome. Oral Surg, Oral Med, Oral Pathol Oral Radiol and Endod. 1997;83(4):453-7.

Nishi M, Stjernsward J, Carlsson P, Bratthall D. Caries experience of some countries and areas expressed by Significant Caries Index. Community Dent Oral Epidemiol. 2002;30:296-301.

Oh TJ, Eber R, Wang HL. Periodontal diseases in the child and adolescent. J Clin Periodontol. 2002;29:400-10.

Oh HML, Chang HH, Boey ML, Feng PH. Infections in systemic lupus erythematosus. Singapore Med J. 1993;34:406-8.

O'Leary TJ. The periodontal screening examination. Journal of Periodontology.1967;38:617-24.

Orteu CH, Buchanan JAG, Hutchison I, Leigh IM, Bull RH. Systemic lupus erythematosus presenting with oral mucosal lesions: easily missed? $\mathrm{Br} \mathrm{J}$ Dermatol. 2001;144:1219-23. 
Pedersen TK, Jensen JJ, Melsen B, Herlin T. Resorption of the temporomandibular condylar bone according to subtypes of juvenile chronic arthritis. J Rheumatol. 2001;28: 2109-15.

Peterson DS, Klein DR. Dental implications for systemic lupus erythematosus. J Oral Med. 1980;35:72-5.

Raj R, Murin S, Matthay RA, Wiedemann HP. Systemic lupus erythematosus in the intensive care unit. Crit Care Clin. 2002;18:781-803.

Reich E, Lussi A, Newbrun E. Caries- risk assessment. Int Dent J. 1999; 49(1):15-26.

Rhodus NL, Johnson DK. The prevalence of oral manifestations of systemic lupus erythematosus. Quintessence Int. 1990;21:461-5.

Romanides N, Marulli RD. Lupus erythematosus in a orthodontic patient. J Clin Orthod. 1999;33: 451-2.

Savioli C, Silva CAA, Ching LH, Campos LMA, Prado EF, Siqueira JTT. Dental aspects in patients with juvenile idiopathic arthritis. Rev Hosp Clin Fac Med S Paulo. 2004;59:93-8.

Savioli C, Silva CAA, Siqueira JTT. Características morfológicas e funcionais do sistema estomatognático em pacientes portadores de artrite reumatóide juvenil. JBO. 2000;25: 70-8.

Silva CAA. Doenças refratárias ao tratamento convencional: como proceder? (Parte 2). Lúpus eritematoso sistêmico Juvenil: nefrite e envolvimento neuropsiquiátrico. Rev Bras Reumatol. 2004;44(1):41-3. 
Siqueira JTT, Camparis C, Savioli C. Disfunção temporomandibular: conceito, classificação, aspectos fisiopatológicos e clínicos. In: Siqueira JTT, Teixeira MJ. Dor: contexto interdisciplinar. Curitiba: Ed Maio. 2003;429-42.

Siqueira JTT. Dor articular - anormalidades da ATM. In: Siqueira JTT, Teixeira MJ. Diagnóstico, terapêutica e qualidade de vida. Curitiba: Ed maio. 2001; p.447-76.

Siudikiene J, Maciulskiene V, Dobrovolskiene R, Nedzelskiene I. Oral hygiene in children with type I diabetes mellitus. Stomatologija. 2005;7(1):24-7.

Souza CRD, Libério SA, Guerra RNM, Monteiro S, Silveira EJD, Pereira ALA. Avaliação da condição periodontal de pacientes renais em hemodiálise. Rev Assoc Med Bras. 2005;51(5):285-9.

Stamm JW. Epidemiology of gingivitis. J Clin Periodontal. 1986;13:360-70.

Story-Lewis PE, Roberts MW, Klippel JH. Oral effects of steroid therapy in a patient with systemic lupus erythematosus: report of a case. JADA. 1987;115:49-51.

Tuggle JW. Systemic lupus erythematosus involvement of the TMJ: A case report. Tex Dent J. 1985;102:11-2.

Vanderas AP, Papagiannoulis L. Multifactorial analysis of the aetiology of craniomandibular dysfunction in children. Int j Paediatr Dent. 2002;12(5):336-46.

Viola MJ, Barbosa RLL, Hilário MOE, Faltin JRK. Avaliação ortodôntica clínica e cefalométrica em pacientes com artrite reumatóide juvenil. Ortodontia. 1996;29:71-80. 
Vogel RI. Periodontal disease associated with amegakaryocytic thrombocytopenia in systemic lupus erythematosus. 1981;52(1):20-3.

World Health Organization - Oral health surveys: basic methods. 4.ed. Geneva, WHO, 1997.

World Health Organization. Significant Caries Index - SIC, 2004.

Welbury RR, Thomason JM, Fitzgerald JL, Steen IN, Marshall NJ, Foster HE. Increased prevalence of dental caries and poor oral hygiene in juvenile idiopathic arthritis. Rheumatology. 2003;42:1445-51. 